\title{
Research Paper \\ Modeling Structural Relationships of Students' Help-Seeking based on Self-Determination and Flourishing: The Mediating Role of Academic Participation and Motivational Beliefs
}

\author{
Azam Samsami ${ }^{1}$, Leila Zoghi ${ }^{* 2}$, Mohamad Mahdi Shariat Bagheri ${ }^{3}$
}

1. Ph.D. Student in Educational Psychology, Central Tehran Branch, Islamic Azad University, Tehran, Iran

2. Assistant Professor, Department of Psychology, Amin University of Law Enforcement Sciences, Tehran, Iran

3. Assistant Professor, Department of Educational Psychology, Central Tehran Branch, Islamic Azad University, Tehran, Iran

Citation: Samsami A, Zoghi L, Shariat Bagheri MM. Modeling structural relationships of students' help-seeking based on selfdetermination and flourishing: the mediating role of academic participation and motivational beliefs. J Child Ment Health. 2021; 8 (2):78-93.

URL: http://childmentalhealth.ir/article-1-1080-en.html
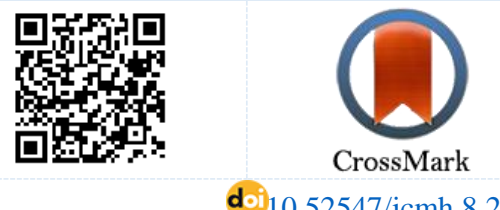

do: $10.52547 / \mathrm{jcmh} \cdot 8.2 .78$

(ङ) 20.1001.1.24233552.1400.8.2.4.5
Open

Access

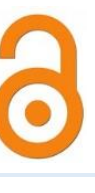

\section{A R T I C L E I N F O}

Keywords:
Help-seeking,
academic participation,
motivational beliefs,
self-determination,
flourishing

Received: 2 Jan 2021

Accepted: 20 Jul 2021

Available: 22 Sep 2021

\section{A B S T R A C T}

Background and Purpose: In the present era, the quality and quantity of education play a crucial role in the future perspective of the individual and is one of the efficacious and appropriate learning strategies in help-seeking or seeking academic help from others. The purpose of the present study was to present a structural model of academic help-seeking based on self-determination and flourishing with the mediating role of academic participation and students' motivational beliefs.

Method: The present study is a developmental-correlational study. The statistical population of this study included all-female high school students in Tehran in the 2019-20 academic year, 454 of whom participated in this study by random cluster sampling as the study sample. The participants answered to the Help-Seeking Questionnaire (Ryan and Pentrich 1997), Basic Needs for self-determination (Ilardi, Leon, Kaiser, and Ryan 1993), the Flourishing Scale (Dainer et al, 2008), Academic participation Scale (Shuffle and Becker, 2006), and Motivational Beliefs Questionnaire (Pentrich et al, 1991). After collecting the questionnaires, the extracted data were analyzed by using structural equation modeling.

Results: The results indicated that the proposed model has a good fit with the data. The results showed a significant relationship between self-determination, flourishing, academic participation, and motivational beliefs with help-seeking $(\mathrm{P}<0.01)$ and also, the results of the Bootstrap test showed that the indirect effect of self-determination on help-seeking through motivational beliefs is 0.147 and the indirect effect of flourishing on help-seeking through motivational beliefs is 0.139 , which is significant at the level of 0.01 .

Conclusion: The results indicated that self-determination and flourishing have a direct effect on students' help-seeking. They also have indirect effects on self-determination and flourishing through motivational beliefs that help to promote students' help-seeking behavior.

* Corresponding author: Leila Zoghi, Assistant Professor, Department of Psychology, Amin University of Law Enforcement Sciences, Tehran, Iran.

E-mail: Leila.zoghi @yahoo.com

Tel: (+98) 2148931558

2476-5740/ (C) 2021 The Authors. This is an open access article under the CC BY-NC-ND license

(https://creativecommons.org/licenses/by-nc-nd/4.0/). 


\section{Quarterly Journal of}

Child Mental Health

Vol. 8, No. 2, Summer 2021

\section{Extended Abstract}

\section{Introduction}

Today, students are one of the main pillars of the country's human resources and have a significant role in the transformation, progress, and excellence of the country. One of the crucial psychological characteristics that influence their academic performance and is effective in the quality and quantity of students' education is help-seeking (2). Helpseeking behavior is analyzed under the two titles of avoiding help-seeking and accepting help-seeking. Research shows that students who use this strategy can dramatically control academic stress and thus achieve high academic performance $(5,6)$. One of the effective factors in students' help-seeking behavior is self-determination (7). It depends on satisfying three psychological needs: autonomy, competence, and relatedness (8). Research has shown that self-determination education is effective on students' help-seeking (9). Although, in the theory of self-determination, the role of environments that develop and inhibit basic psychological needs have been considered, but the role of the student's internal resources in interacting with the environment to function optimally is one of the issues that need to be addressed. One of the most crucial factors in the growth and development of the people studying is the issue of flourishing (4). Flourishing is a construct in positive psychology that refers to a kind of life with constant optimism in human actions. Students with high levels of flourishing can maintain their focus and attention on homework (10).

Another factor influencing students' help-seeking behavior is academic participation (12). Academic participation is a kind of psychological effort to learn, understand and master the knowledge, skills, and arts that academic activities are there to promote them. Researchers believe that academic participation can be effective in students' help-seeking (16, 17). Helpseeking behavior in students is influenced by the attitudes and motivational beliefs they adopt during their education (18). Motivational beliefs are a set of personal and social criteria that people refer to act. Researchers believe that there is a relationship between motivational beliefs and academic helpseeking behaviors $(16,18,20)$. Researches also suggest the relationship between self-determination and motivational beliefs $(21,22)$ and the relationship between flourishing and motivational beliefs (23).

Identifying the associated factors with help-seeking can prevent the harmful phenomenon of academic failure. It provides a basis for improving the academic performance of learners. Therefore, the purpose of this study is to investigate the structural model of academic help-seeking with selfdetermination and students' flourishing with the mediating role of academic participation and motivational beliefs.

\section{Method}

The present study is a developmental-correlational study. The population included all-female high school students in Tehran in the 2019-20 academic year, from which 454 people were selected. Data collection instruments were the help-seeking behaviors questionnaire (24), self-determination basic needs (26), flourishing scale (28), academic participation scale (30), and motivational beliefs questionnaire (32). After conducting the research, the data were analyzed by using SPSS23 and AMOS23 software.

\section{Results}

According to the results of the correlation matrix, all variables in the study had a positive and significant correlation with each other at the level of 0.01 . The model's fit indices were examined to test the research hypotheses by the structural equation modeling method. All corrected indices (RMSEA $=0.061$, $\mathrm{SRMR}=0.062, \mathrm{TLI}=0.939, \mathrm{NFI}=947, \mathrm{CFI}=0.966, \mathrm{GFI}=$ $0.943, \mathrm{X} 2 / \mathrm{df}=2.61)$ confirmed the fitness of the proposed model of the research. The confidence interval of the bootstrapping with 2000 resampling for mediating motivational beliefs between self-determination and help-seeking was $0.091-0.234(\mathrm{p}<0.01)$.

The confidence interval of the bootstrapping of motivational beliefs between flourishing and help-seeking also were 0.080.224 ( $\mathrm{p}<0.01)$; Therefore, it can be said that motivational beliefs play a mediating role in the relationships of selfdetermination-help-seeking and flourishing-help-seeking. In this study, the results indicate that the proposed model has a good fit with the data. The results of the bootstrap test showed that the indirect effect of self-determination on help-seeking through motivational beliefs was 0.147 and the indirect effect of flourishing on help-seeking through motivational beliefs was 0.139 which were significant at the level of 0.01 .

\section{Conclusion}

The purpose of this study was to investigate the structural relationships between students' academic help-seeking based on self-determination and flourishing with the mediating role of academic participation and motivational beliefs. The results showed that motivational beliefs are related to academic helpseeking; the results of this study are consistent with studies (18, $16,20)$ that believe that motivational beliefs are related to helpseeking and even motivational beliefs can predict help-seeking. Another finding of this study indicates the relationship between self-determination and motivational beliefs. This finding is consistent with the results of studies $(21,22)$ that believe there is a close relationship between self-determination and motivational beliefs. The findings also show the relationship between flourishing and motivational beliefs. This research finding is consistent with the results of research (23) which believes that desirable motivational beliefs in students predict flourishing in them.

The other finding of the research, which is the result of the model, showed that the variable of motivational beliefs plays a mediating role between the variables of self-determination and help-seeking. This finding is consistent with the results of studies $(16,20-22)$ that have emphasized the relationship 


\section{Quarterly Journal of Child Mental Health}

Vol. 8, No. 2, Summer 2021

between these variables. The results of this study also showed that the variable of motivational beliefs could play a mediating role between flourishing and help-seeking. No research was found in predicting help-seeking based on flourishing; but this finding is consistent with the research of (23) that shows the relationship between motivational beliefs and flourishing. In general, it can be said that motivational beliefs play a mediating role in the relationships of self-determination-help-seeking and flourishing-help-seeking.

Lack of control over demographic variables such as parents' education, economic status, and the number of siblings were some of the limitations of this study. Therefore, it is suggested that these variables be controlled as much as possible in future studies. It is suggested that in future studies, models based on gender segregation be presented for the comparison between male and female students in academic help-seeking behavior to be possible. According to the research findings, this model can be used for active involvement of students in the academic environment and in achieving academic goals, especially in active learning methods, study camps, extracurricular classes, etc., and to generalize lessons.

\section{Ethical Considerations}

Compliance with ethical guidelines: This research is extracted from Ms. Azam Samsami's Ph.D. dissertation in the major of educational psychology at the Islamic Azad University, Central Tehran Branch, whose proposal was approved on 09/07/2019 and defended with the dissertation code 10120702981008 . The performing permission has been announced by the university letter number $72509 / 8167$ dated 29/09/2019. Ethical considerations such as confidentiality, the confidentiality of identity information, and data analysis are also fully considered in this study.

Funding: This study was conducted without sponsorship and at the personal expense of the authors.

Authors' contribution: The first author of this article is the main researcher and the second, and third authors have acted as supervising and project consulting professors, respectively.

Conflict of interest: Doing this research has not resulted in any conflict of interest for the authors, and the results have been reported completely transparently and without bias.

Acknowledgments: We would like to thank the education officials of Tehran, especially the principals, deputies, teachers, and counselors of the schools and the students participating in this research. 


\section{مدل يابى روابط ساختارى كمككطلبى تحصيلى داش آموزان بر اساس خودتعيين گرى و شكفتكى: نقش ميانجى مشار كت تحصيلى و باورهاى انتيزشى}

\section{اعظم صمصامى'، ليلا ذوقى *'، محمد مهدى شريعت باقرى}

1. دانشجوى دكتراى روانشناسى تريتى، واحد تهران مركزى، دانشكاه آزاد اسلامى، تهران، ايران اندان

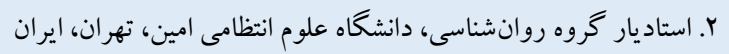

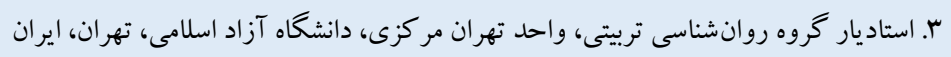

\section{?}

زمينه و هدف: در عصـر حاضـر كيفيت و كميت تحصسيل، نقش مهمى در آينده فرد ايفا مى كند و از جمله راهبردهاى يادگيرى مؤثر و

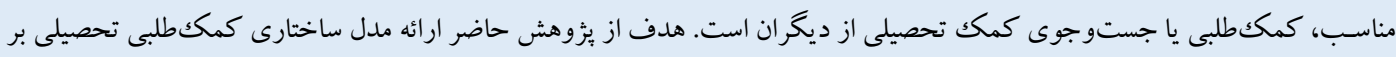

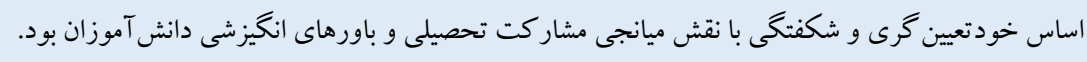

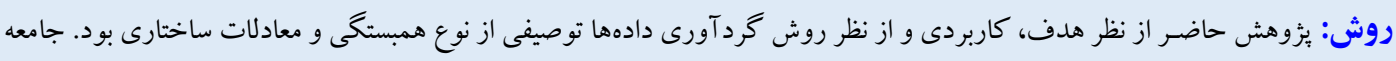

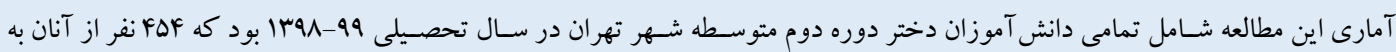

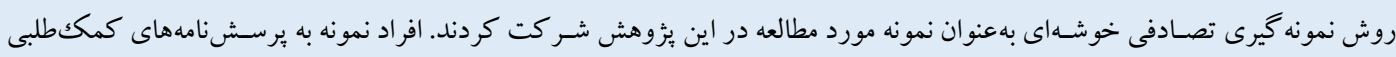

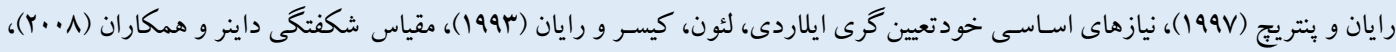

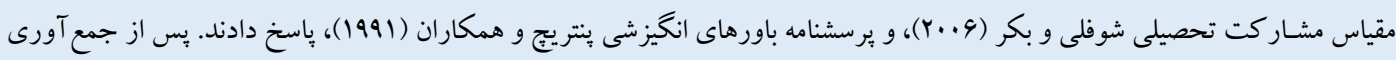

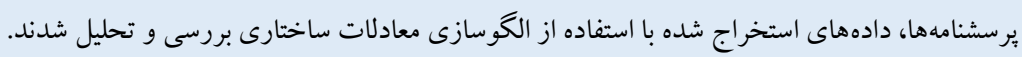

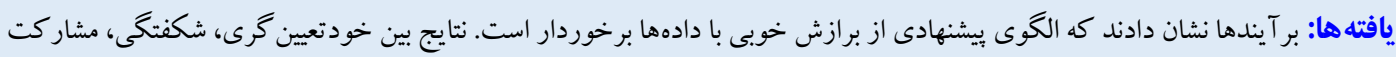

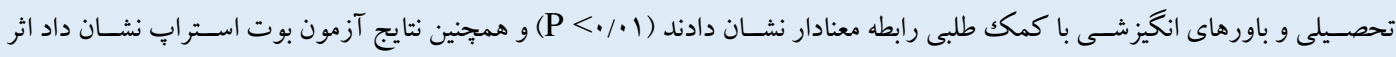

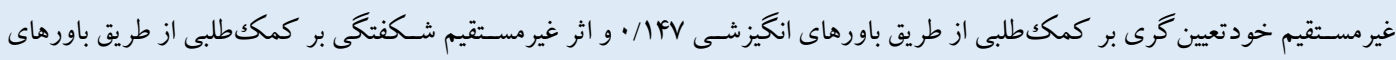

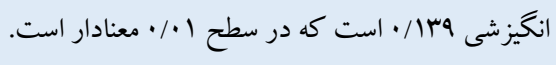
نتيجه كيرى: نتايج نشـان دادند كه خودتعيين گرى و شـكفتكى بهطور مسـتقيم بر كمككطلبى دانش آموزان مؤثر هسـتند و اثر غيرمسـتقيم

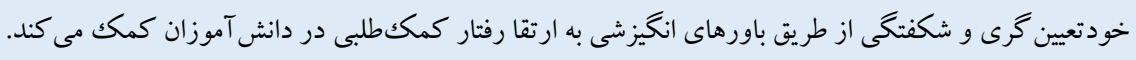

مشخصات مقاله

كليدوازهها:

كمككطلبى،

مشار كت تحصيلى، باورهاى انخيزشى، خودتعيين گرى، باورهاي انحيزت، شكفتكى

دريافت شده: س / • /

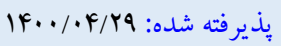

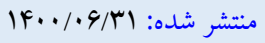

* نويسنده مسئول: ليلا ذوقى، استاديار گروه روانشناسى، دانشگاه علوم انتامى امين، تهران، ايران.

رايانامه:yahoo.com

تلفن: 


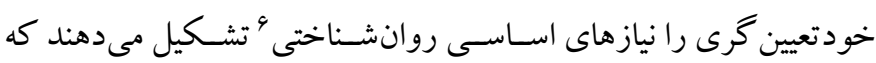

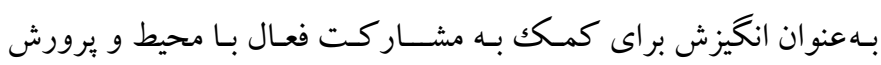

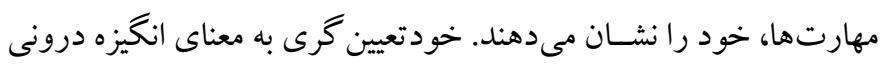

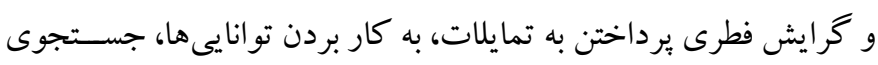

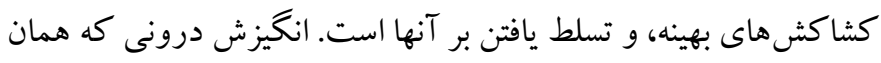

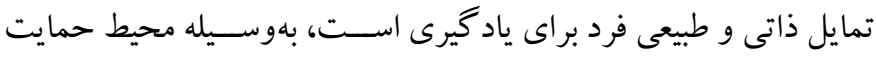

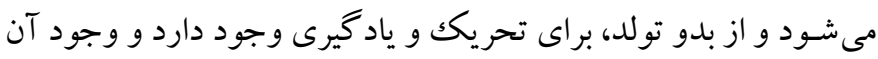

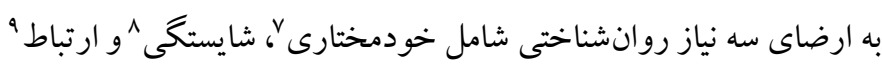

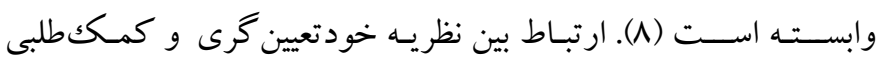

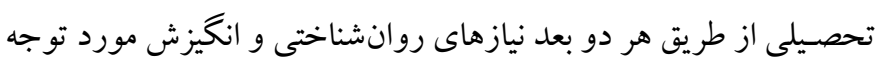

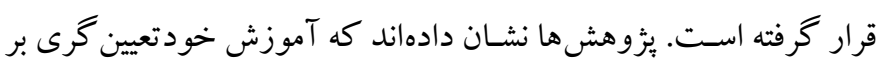

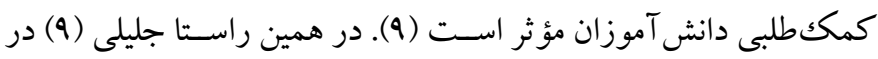

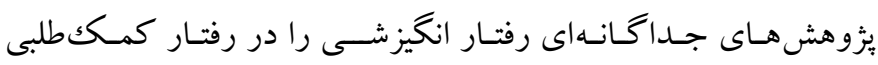
دانش آموزان مؤثر دانسته است.

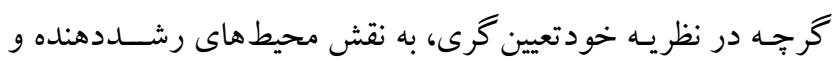
بازدارنده نيازهاى اسـاسى روانشـناختى توجه شــده است، اما نقش منابع

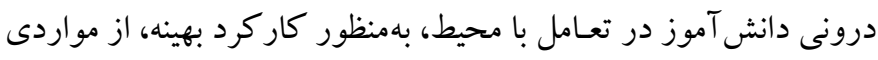

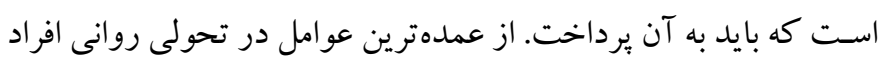

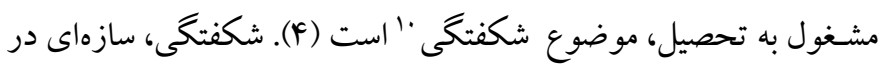
روانشـاسـى مثبت اسـت كه به نوع زندكى تو أم با خوش بينى دائمى، در

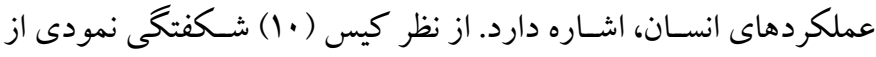

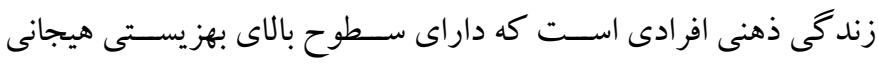

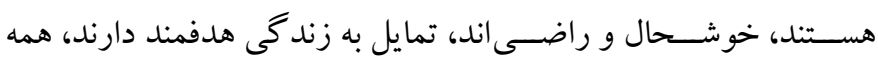

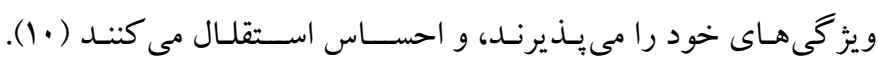

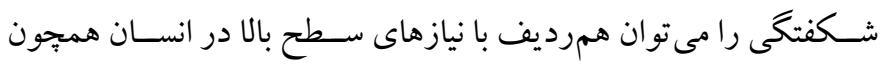

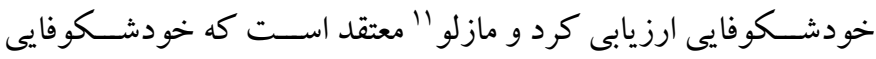

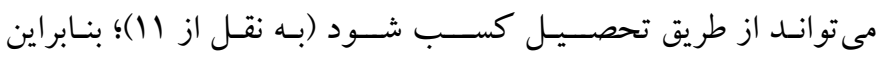

7. Autonomy

8. Competence

9. Relatedness

10. Flourishing

11. Maslow
مقلدمه

امروزه دانش آموزان از ار كان اصــلى نيروى انسـانى كشـور محســوب مى شـــوند و نقش زيادى در تحول، يِيشــــت و تعالى كشـــور دارند. از اينرو، توجه به سـلامت و سرزندكى روانى -اجتماعى' و تحصيلى آنها از اهميـت ويثه اى برخوردار اســـ؛ در نتيجه همواره برنامهريزان، مديران، معلمان، و والدين اين دانش آموزان در تلاش هسـتند تا شـر ايطى را فراهم كنند كه كار آيى اجتماعى و تحصــيلى آنان بالا برود ( (1). يكى از عوامل بســــار مهم و اثرگـذار در عملكرد تحصــلى دانش آموزان عوامـل روانشــاختى آنان اسـت. از جمله ويثز گیى هاى روانشــناختى مهمى كه عملكرد تحصــلى آنان را تحت تأثير قرار مىدهد و در كيفيت و كميت تحصـيل دانش آموزان مؤثر اسـت، كمككطلبى ^يا جسـت جوجوى كمكك تحصيلى از ديخران است (Y). بهطور معمول دانش آموزان با موقعيتهايى مواجه مىشوند كه در آن شر ايط نمى توانند خواسته هاى خود را بر آورده كنند و براى انجام تكاليف خود به كمكك و نصـيحت ديخر ان نياز دارند.

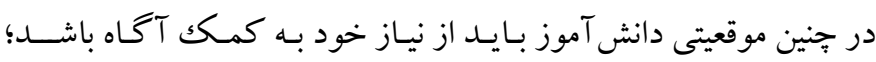
تصسميم به جسـتوجوى كمكك بكيرد، و راهبردهايى رابر اي استفاده از كمـك ديكران بـه كـار گيرد (r). رفتـار كمـككلبى تحست دو عنوان

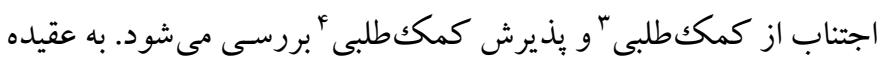
نيومن (F) كمـك طلبى تحصـيلى، جســتو جوى كمـك از ديخرى به

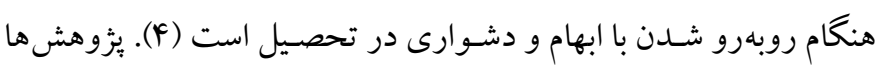
نشـان مى دهند كه كمككطلبى تحصسيلى راهبرد ياد گيرى مهمى اسـت و دانش آموزانى كه از اين راهبرد استفاده مى كنند قادر هستند تنيدكى هاى تحصـيلى را بهطور جشــميرى مهار كرده و در نتيجه عملكرد تحصسيلى بالايى داشته باشند (هو و). يـكى از عـوامـل مـؤثـر در رفتـار كـمـككطلـبـى دانش آموزان، خود تعيين گرىه است (V). نظريه خود تعيين گرى بهطور ويزه، به تحليل و

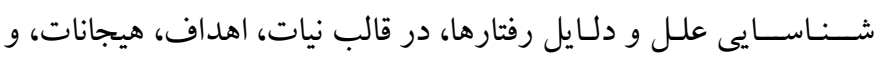

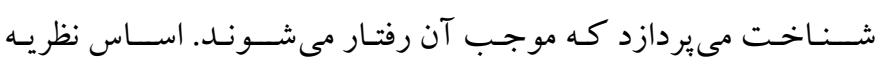

1. Psychosocial vitalistic

2. Help-seeking

3. Help -avoidance

4. Help acceptance

5. Self-determination

6. Basic psychological needs 
موقعيت هاى مختلف ممكن اسـت تغيير كنند (19). يثزوهشخران معتقداند بين باورهاى انخيزشى و رفتارهاى كمكك طلبى تحصيلى رابطه وجود دارد

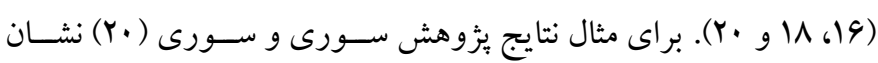

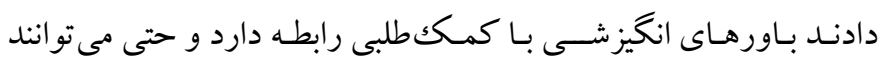

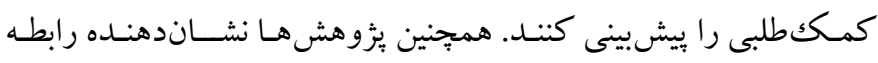

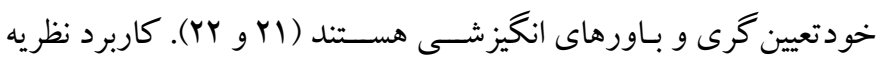

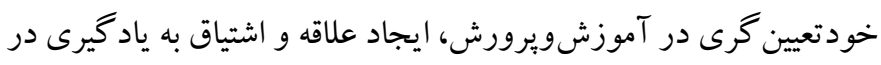

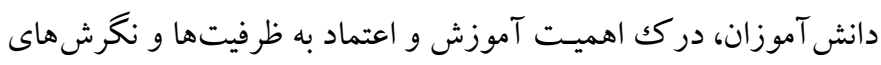

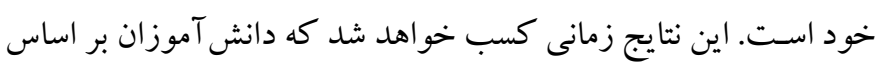

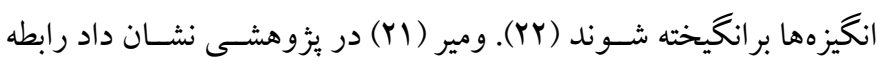

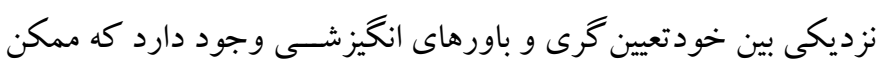

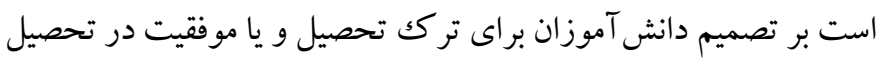

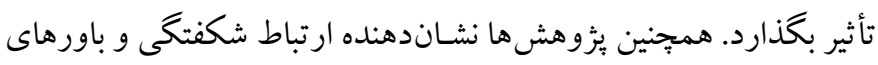

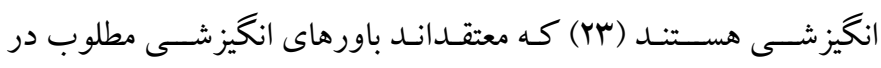
دانش آموزان، بيش بين شكفتخى و كاهش بى حوصلكى در آنان است. عوامل متعددى در كمكك طلبى تحصسيلى دانش آموزان نقش دارد كه

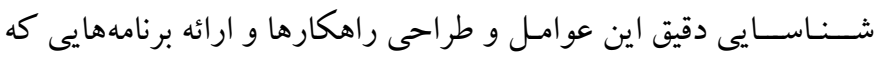

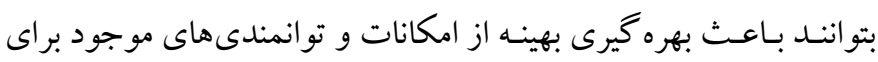
نيل به بازدهى رضايت بخش و ييشرفت تحصيلى آنان شود، حائز اهميت

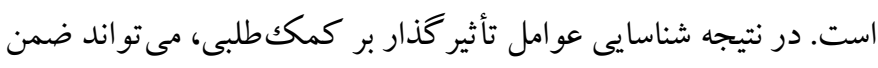

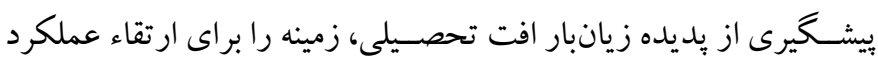

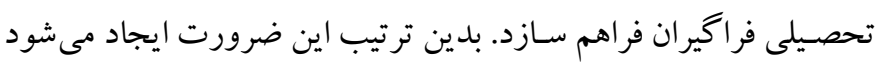

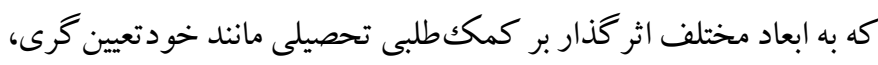

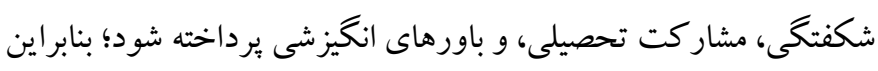

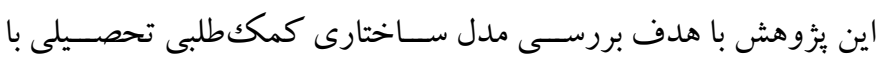

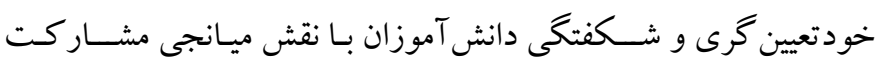

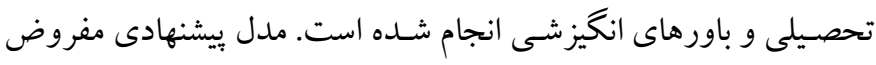
در شكل زير نمايش داده شده است.
دانش آموزان داراى سطح بالاى شـكفتكى مى توانند تمركز و توجه خود را روى تكاليف حفظ كنند (·) (1). از ديخر عوامل اثر گذار بر رفتار كمككطلبى دانش آموزان، مشار كت

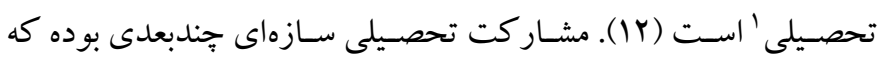

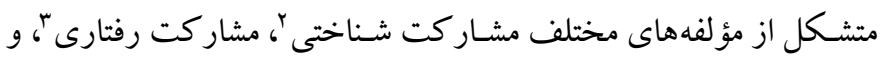

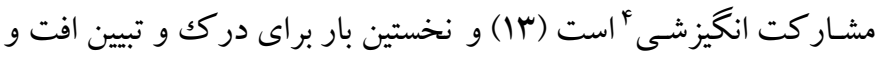

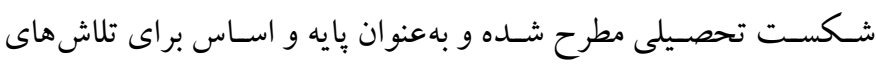

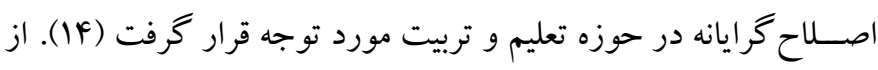

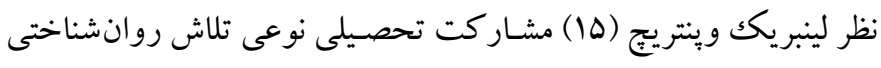

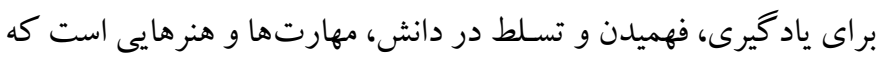

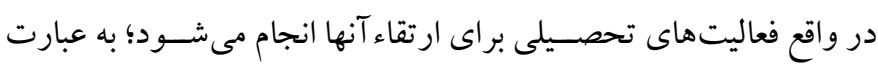

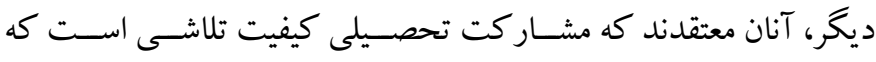

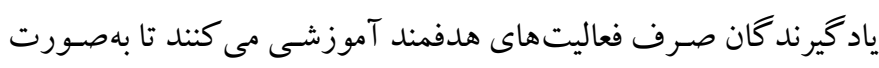

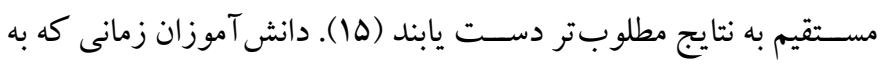

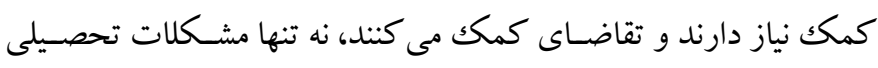

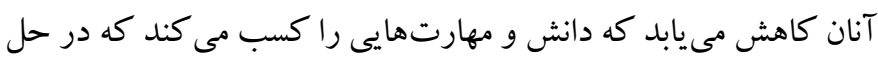

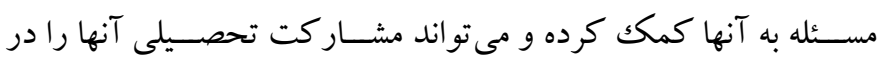

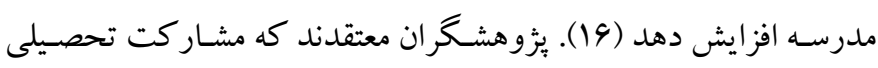

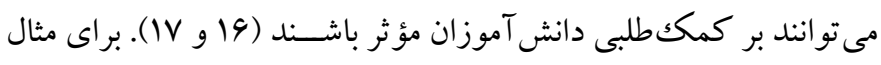

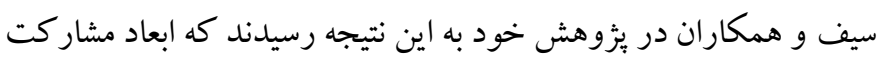
تحصيلى بهطور غيرمستقيم در كمكك طلبى دانش آموزان مؤثر است (IV)

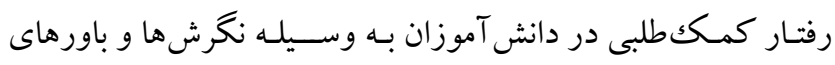
انكيزشــى ه كه در طى دوران تحصـيل اتخاذ مى كنند، تحت تأثير قرار

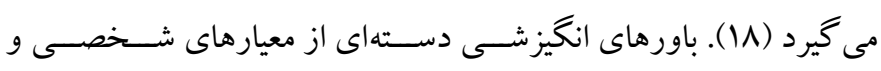
اجتماعى هسـتند كه افراد براى انجام يكك عمل به آنها مر اجعه مى كنئد.

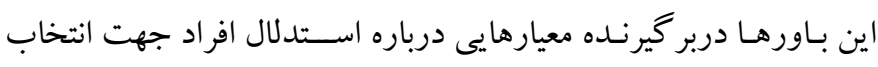

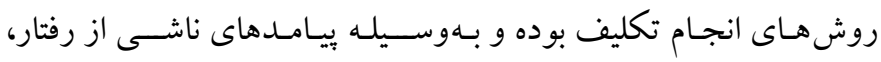

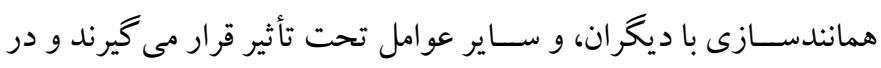

4. Motivational participation

5. Motivational beliefs
1. Academic participation

2. Cognitive participation

3. Behavioral participation 


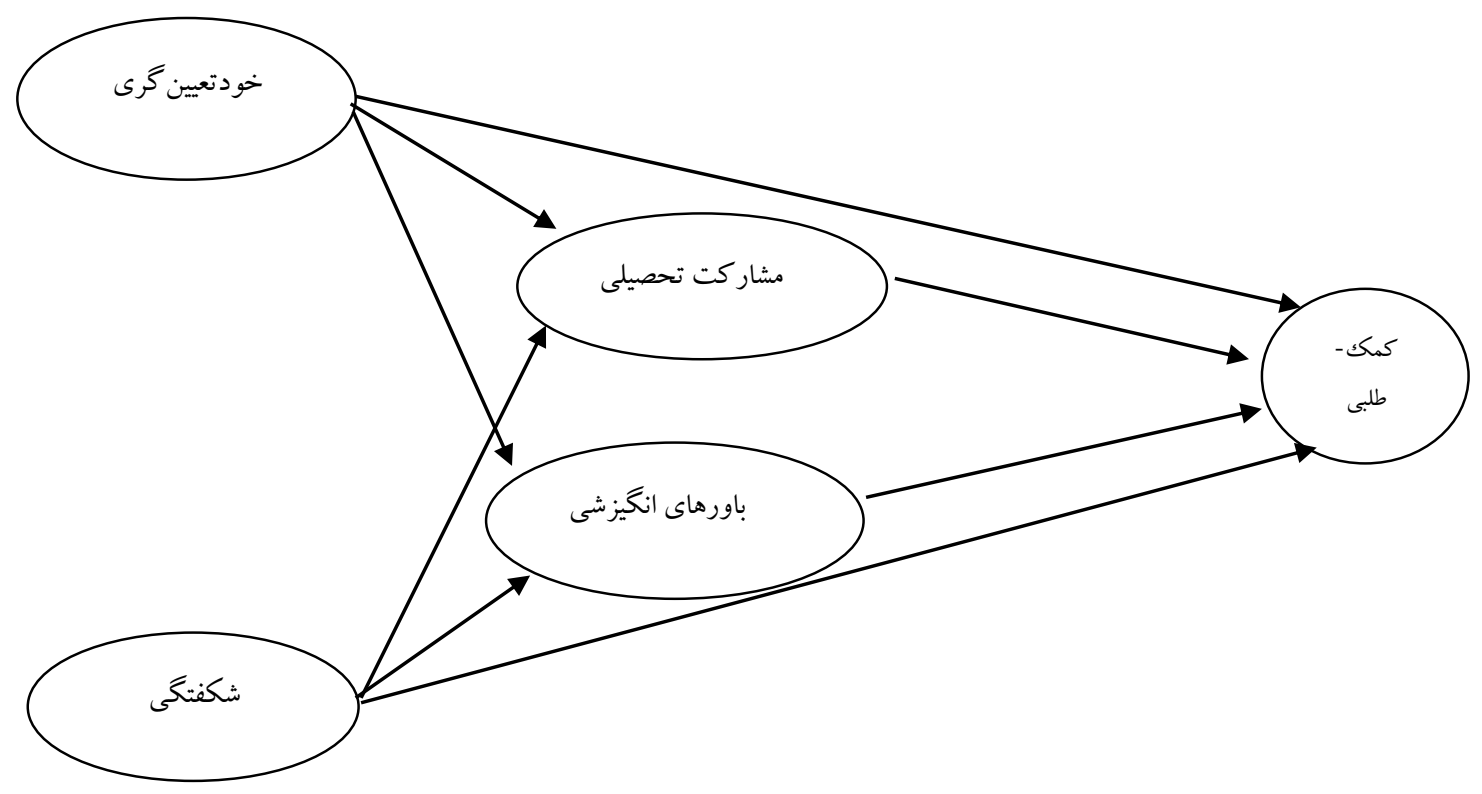

شكل 1: مدل بيشنهادى (محققساخته)

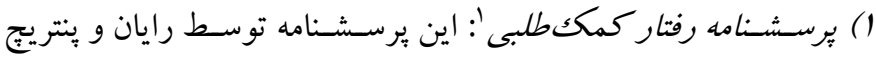

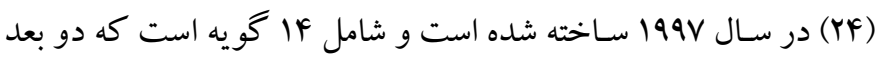

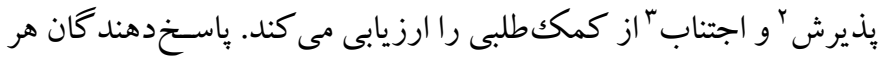

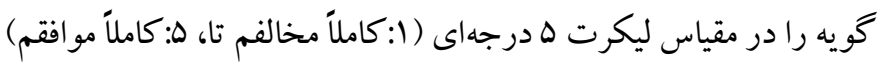

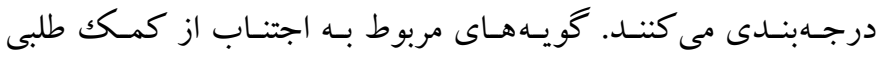

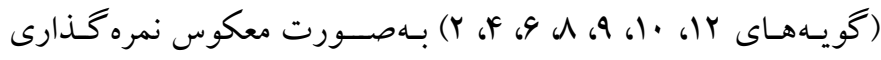
مىشوند و دامنه نمرات در اين مقياس fl أتا •V است. نمره بالاتر به معناى

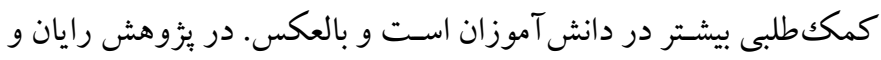
يينتريج (YY) اعتبار برسـشـنامه با استفاده از آلفاى كرونباخ بر ایى اجتناب

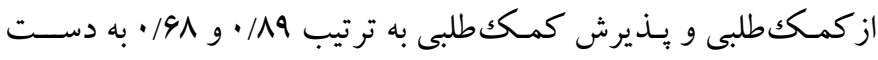

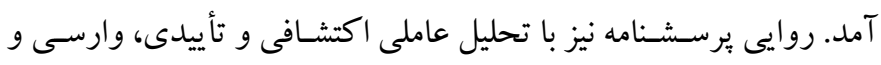

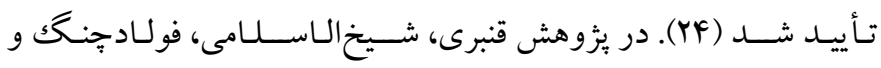

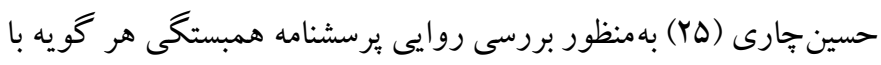

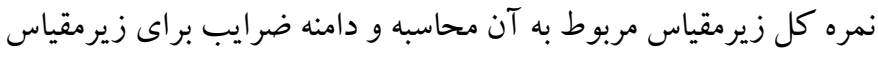

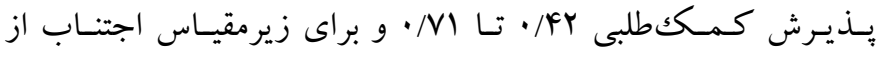

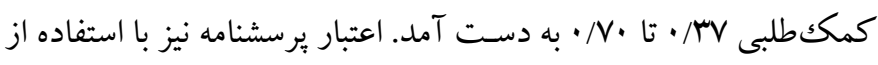

3. Avoid
الف) طرح هزؤهش و شر كت كنند كان: روش يزٔوهش حاضر توصيفى

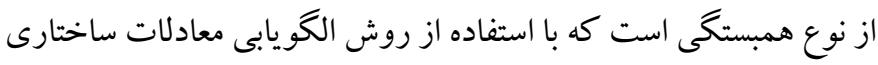

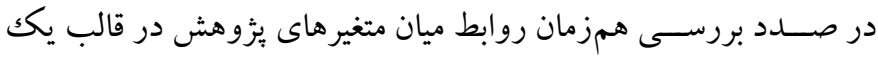

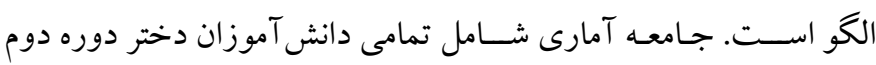

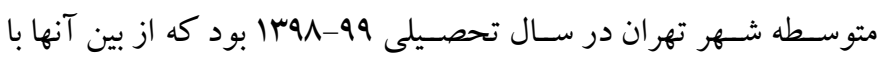
روش نمونه گيرى تصادفى خوشهاى تعداد FDF نفر انتخاب شدند. ملاكك

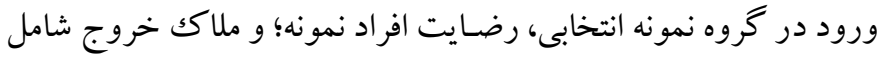

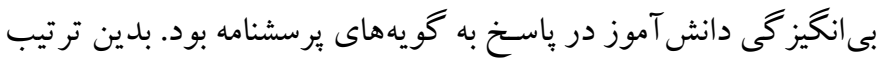

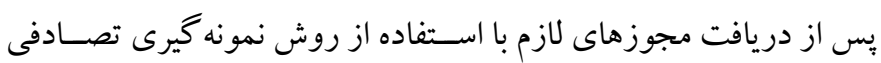

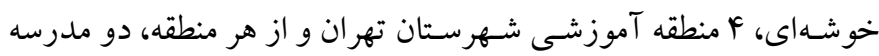
دخترانه دوره دوم متوسطه، و در نهايت از هر مدرسه F كلاس به تصادف

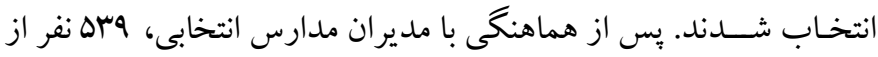

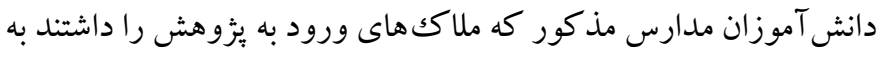

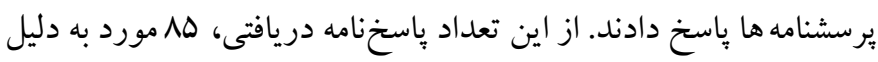

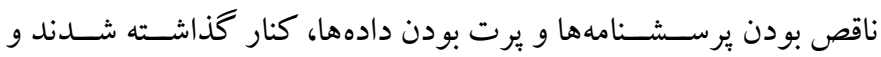
دادههاى FDF نفر وارد تحليل شد.

1. Help-Seeking Behaviors Questionnaire 2. Accept 
روانشـناسـى انجام شــد (Y9). آلفاى كرونباخ در يزوهش حاضـر AF/· محاسبه شد.

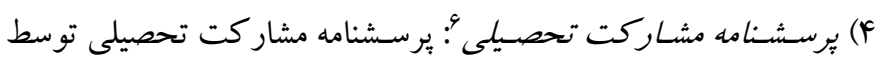

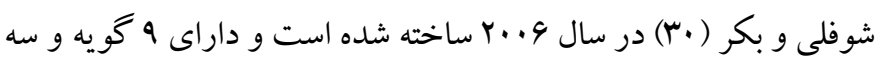

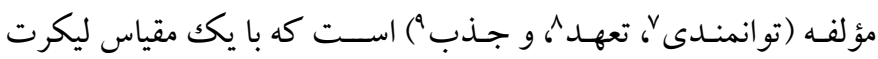

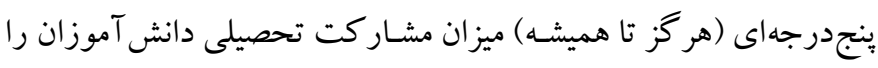

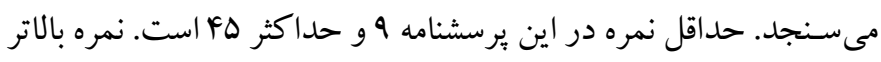

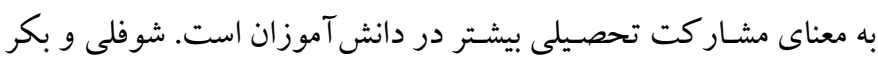

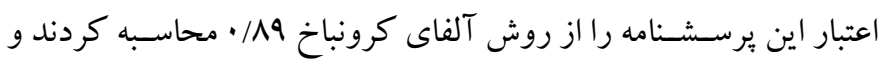

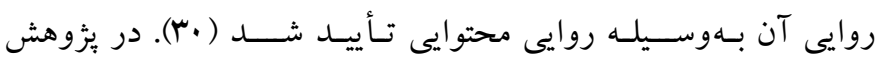

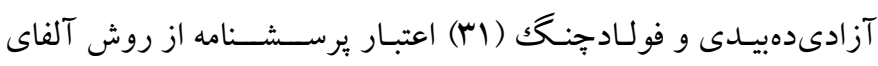

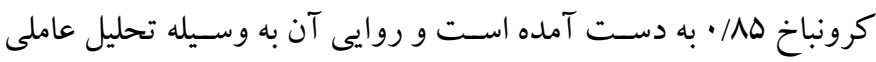

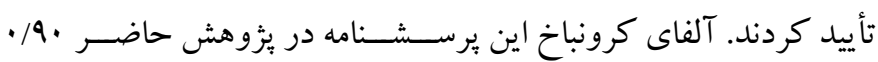

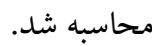

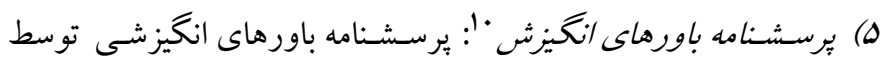

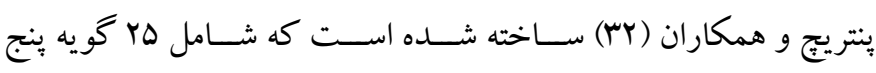
كزينهاى اسـت كه بر اسـاس طيف ليكرت درجهابندى شـده اسـت. مؤلفه

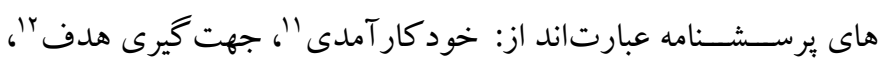

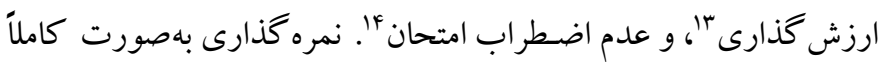

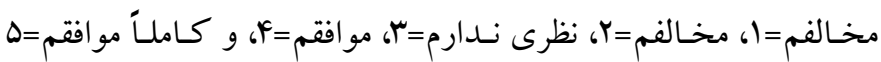

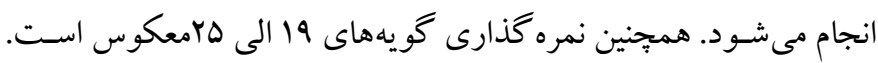

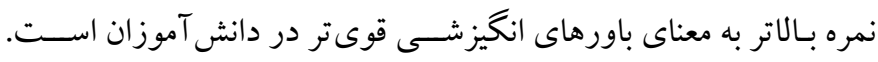
ينتريج و دى گروت روايى اين مقياس را با اسـتفاده از تحليل عاملى تأييد

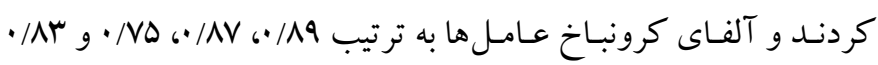

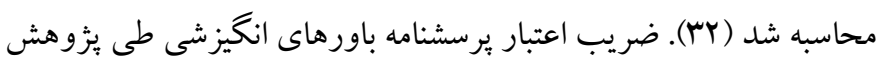

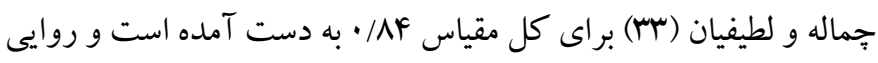

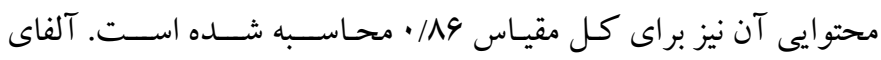

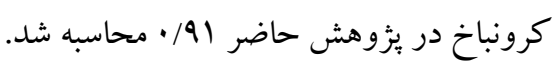

8. Committal

9. Absopption

10. Motivational Beliefs Questionnaire

11. Self-efficacy

12. Goal orientation

13. Valuation

14. No exam anxiety
ضـــــب آلفـاى كرونبـاخ براى يـــيرش كمـككلبى و اجتنـاب از

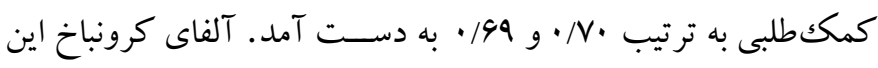
يرسشنامه در يثزوهش حاضر NA / • محاسبه شد.

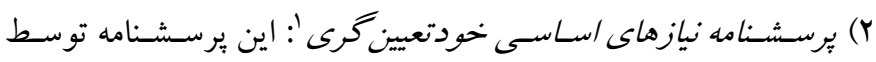

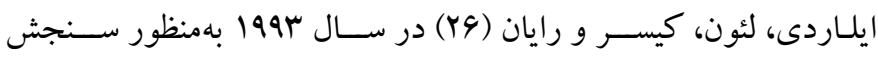
نيازهاى روانشـناختى اسـاسى سـاخته شد كه شامل اب كويه است كه با طيف ه درجسهاى ليكرت از كـاملاً موافق (نمره ه) تا كاملاً مخالف (نمره

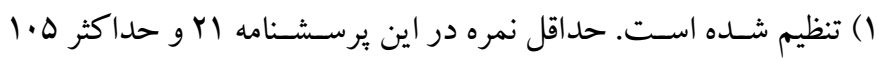

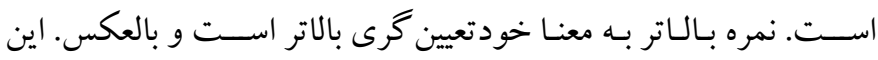

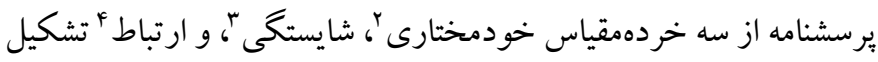

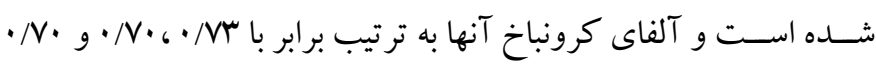

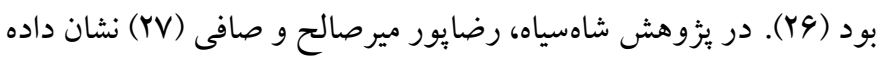

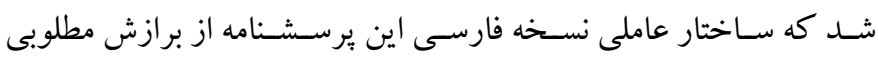

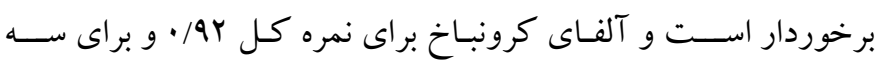

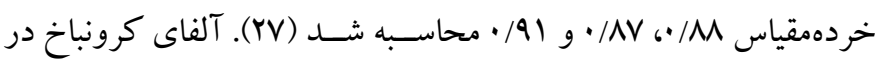
يُزوهش حاضر براى نمره كل 91/ • به دست آمد.

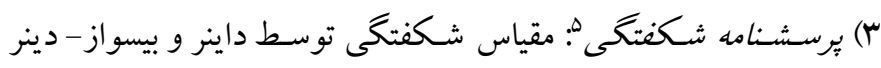

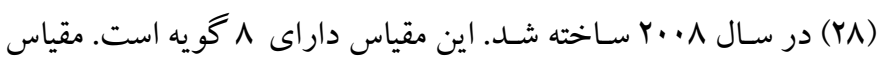
شكفتكى، بر درجهبندى هفت كانه ليكرت تنظيم شده است. حداقل امتياز

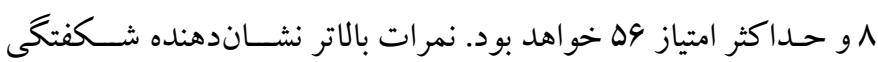

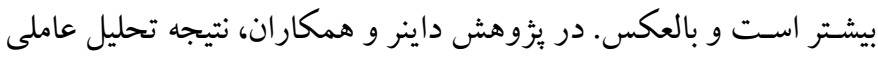

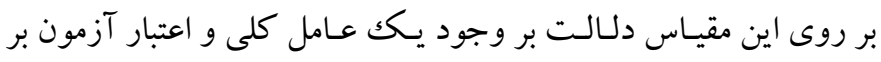

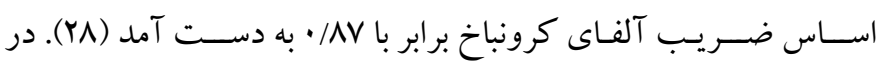

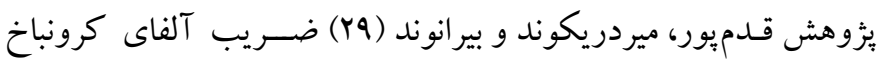

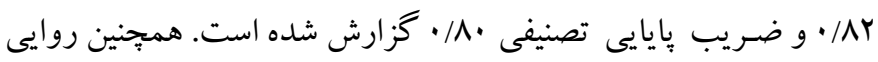

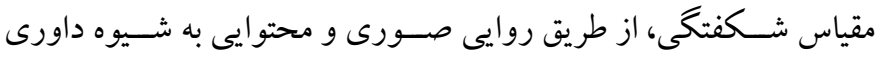
تخصصى و از حيث انطباق با بنيان نظرى آن توسط بـ تن از متخصصيقان

1. Self-Determination Basic Needs Questionnaire

2. Autonomy

3. Competence

4. Relatedness

5. Flourishing Questionnaire

6. Academic participation Questionnaire

7. Potency 
ابهـام برداخـت، همجينين بـه دانش آموزان اطمينـان كـافى داده شــــ كـه سـوالات، نظرات آنها را مى سـنجد، ياسخ درست يا غلط نداشته، صداقت در ياســخ گويى مورد توجه بوده، ياســخ هاى آنها محرمانه خو اهد ماند، و

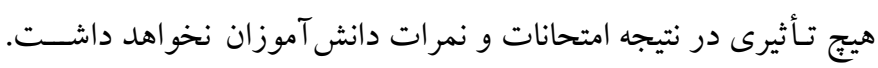
يسس از اجراى ئزوهش، دادههـا بـا اســتفــاده از نرمافزار SPSS و و AMOS 23

إفته در جدول ا شاخص هاى توصيفى متغيرهاى يُوهش ارائه شده است.
ج) روش اجر ا: بعـد از كســب مجوزهاى لازم از دانشــاه آزاد واحد تهران مركزى و همجينين سازمان آموزشويرورش شهرستان تهران، افراد

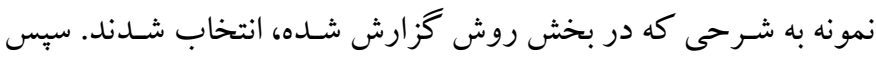
بهمنظور فراهم آوردن جّّى مناسـب جهت اجراى مطلوب يزوهش و بالا بردن ميزان اعتبار درونى آن تدابيرى به كار بسته شد: توزيع و جمع آورى يرسشنامه ها بهمنظور دقت بالا و جلو گيرى از كاستىهاى عمدى يا سهوى

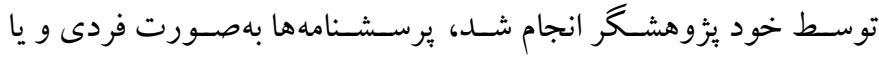
كروهى به دانش آموزان تحويل داده شد، نحوه ياسخ دادن به يرسشنامهها

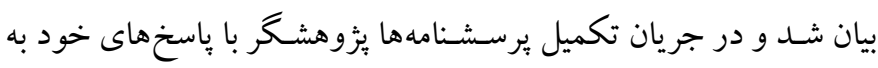
سؤالهاى دانش آموزان، آنها را راهنمايى كرده و با صبر و حوصله به رفع

\begin{tabular}{|c|c|c|c|c|c|c|}
\hline كشيدىى & كجى & بيشترين & كمترين & انحراف استاندارد & ميانكين & متغير \\
\hline .1994 & $-\cdot / F \Delta r$ & 99 & $r$. & G/Ar & $\Delta r / 99$ & كمككطبى \\
\hline$-\cdot / r \Delta r$ & $-\cdot /$ TrF & $1 \cdot 0$ & kq & $1 / 1 / 10$ & $\| F / A F$ & خود تعيين گرى \\
\hline $1 / \wedge 9$ & $\cdot / Y 49$ & $\Delta 9$ & IV & $11 / 49$ & Fq/9F & شكفتخى \\
\hline$-\cdot / I r \wedge$ &.$- / 9 \mathrm{TV}$ & fo & 9 & N/YG & $\mathrm{rl} / \mathrm{M}$ & مشار كت تحصيلى \\
\hline$-\cdot / 4 \cdot q$ & $-\cdot / Y F$ & Iro & $\Delta$. & $10 / 11$ & Qr/A9 & باورهاى انگيزشى \\
\hline
\end{tabular}

در اين مطـالعـه فرض نرمـال بودن جِندمتغيرى با محاســبه شــاخص

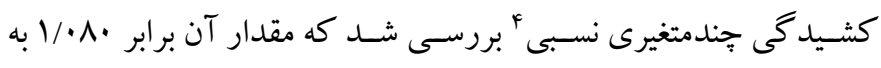
دست آمد. بنتلر (MY) معتقد است درصورتى كه ارزش اين شاخص بيشتر از ب نباشـــ، نرمال بودن جِندمتغيرى محقق شــده اســـ؛ بنابر اين توزيع تمامى تر كيب هاى متغيرها نرمال است. بررسى بيش فرض عدم وجود هم خطى جند گانه هبهوسيله وارسى ماتريس همبستگى بين متغيرهاى مشهود انجام شــــ. بررســى اين ماتريس حاكى از عدم وجود هم خطى جندكًانه

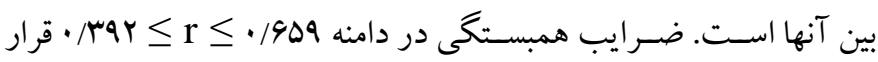
دارند. ضـرايب همبسـتِى كه بالاى ه / • باشـند در تخمين صسحيح مدل

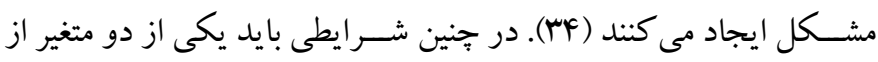

$$
\text { تحليل كنار كذارده شود. }
$$

قبـل از ارزيـابى مدل اندازهگيرى و مدل ســاختارى، ييشفرضهاى مهم مــل يـابى معـادلـات ســاختارى شــامل نرمال بودن تككمتغيرى' و و جندمتغيرى ץ' و عدم وجود همخطى جند كانه مورد بررسـى قرار كرفت.

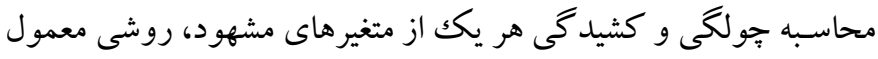
براى ارزيـابى نرمـال بودن تـك متغيرى اســت. در اين مطسالعسه جولكى متغيرهاى مشــاهدهيذير در دامنه 9MV/ •- تا Y99/ • و كشـيدكى آنها در

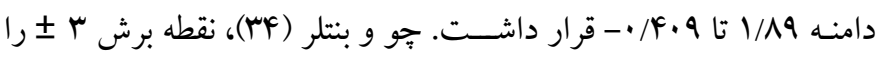

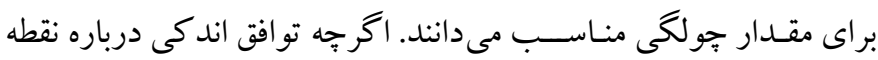
برش كشــيدكى وجود دارد، با اين حال بهطور كلى مقادير بيش از · ـ براى اين شـاخص مسئله آفرين بوده و مقادير بيش از · ب 土 نتايج به دست آمده را نامعتبر مىســازد (ها). دادههاى برت جندمتغيره توســط آزمون

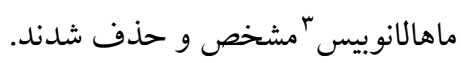

جدول r: ماتريس همبستغى ييرسون متغير هاى يخوهش

4. Relative multivariate kurtosis

5. Multi-collinearity
1. Univariate normality

2. Multivariate normality

3. Mahalanobis distance 


\begin{tabular}{|c|c|c|c|c|c|}
\hline باورهاى انكيزشى & مشاركت تحصيلى & خود تعيين كرى & شكفتكى & كمك طلبى & متغير \\
\hline & & & & 1 & كمك طلبى \\
\hline & & & 1 & •/ $/$ M Y & شكفتخى \\
\hline & & 1 & $.1949 \%$ & - $/$ FFY & خود تعيين گرى \\
\hline & 1 & 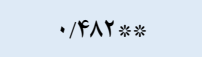 & $\cdot / \Delta \wedge \Gamma^{*}$ & $\cdot / \Delta \cdot \Delta$ 拳光 & مشاركت تحصيلى \\
\hline 1 & .1909 米䓋 & $\cdot / 9 \cdot r_{\text {䄅米 }}$ & 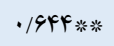 & . & باورهاى انگگيزشى \\
\hline
\end{tabular}

مى كند. ارزيابى اين مدل با اسـتفاده از روش تحليل عاملى تأييدى انجام

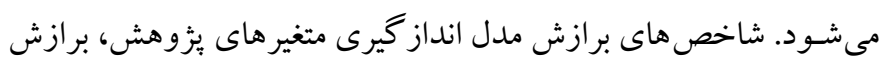

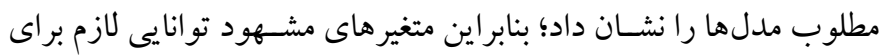

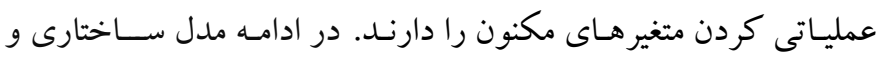
مفهومى بُزوهش مورد بررسى قرار خرفت.
همانطور كه در جدول Y ملاحظه مى شود تمامى متغيرهاى حاضر در يزوهش در سطح 1 • • همبستخى مثبت و معنادارى با يكديخر داشتند.

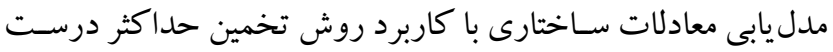

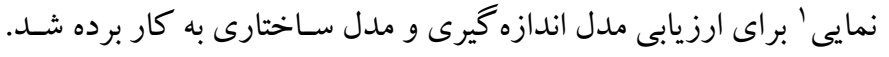

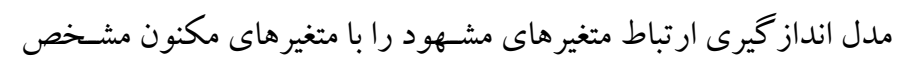

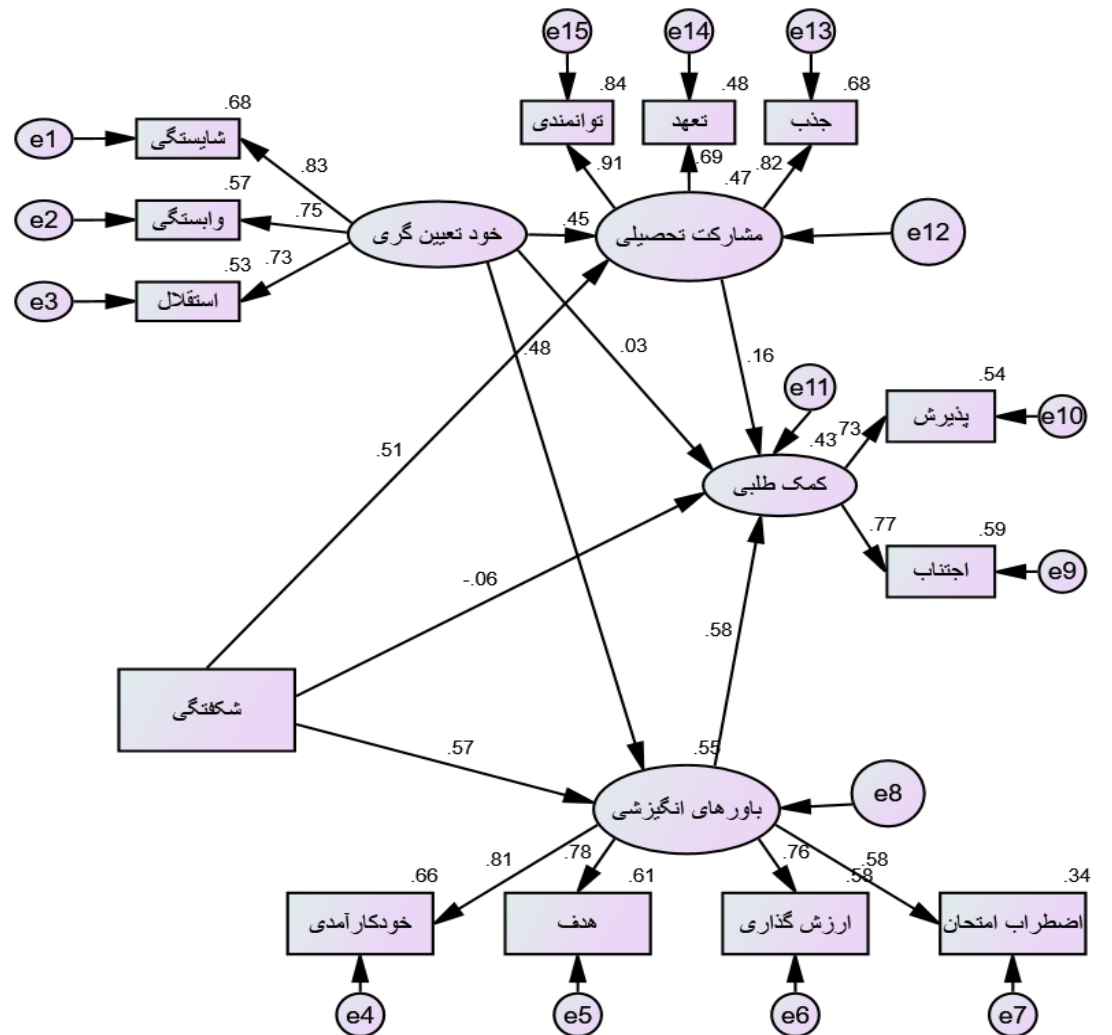

شكل ז: مدل استاندارد قبل از اصلاح: رابطه كمككطلبى با خودتعيين كرى و شكفتكى با ميانجى كرى مشاركت تحصيلى و باورهاى انتيزشى در دانش آموزان

نيسـت (كـه البتـه با حضـــور متغير ميانجى اين انتظار مىرفت). همجِنين رابطه متغير ميانجى مشاركت تحصيلى با كمك طلبى معنادار نيست. براى
وزنهاى ركرسيون و سطح معنادارى نشان مى دهد رابطه مستقيم بين متغيرهـاى مســتقـل شــكفتكى و خود تعيين گرى با كمكك طلبى معنادار 
به برازش رسيدن مدل، متغير مشار كت تحصيلى كه با كمك طلبى رابطه نداشت از مدل حذف شد و مدل دوباره مورد بررسى قرار كرفت.

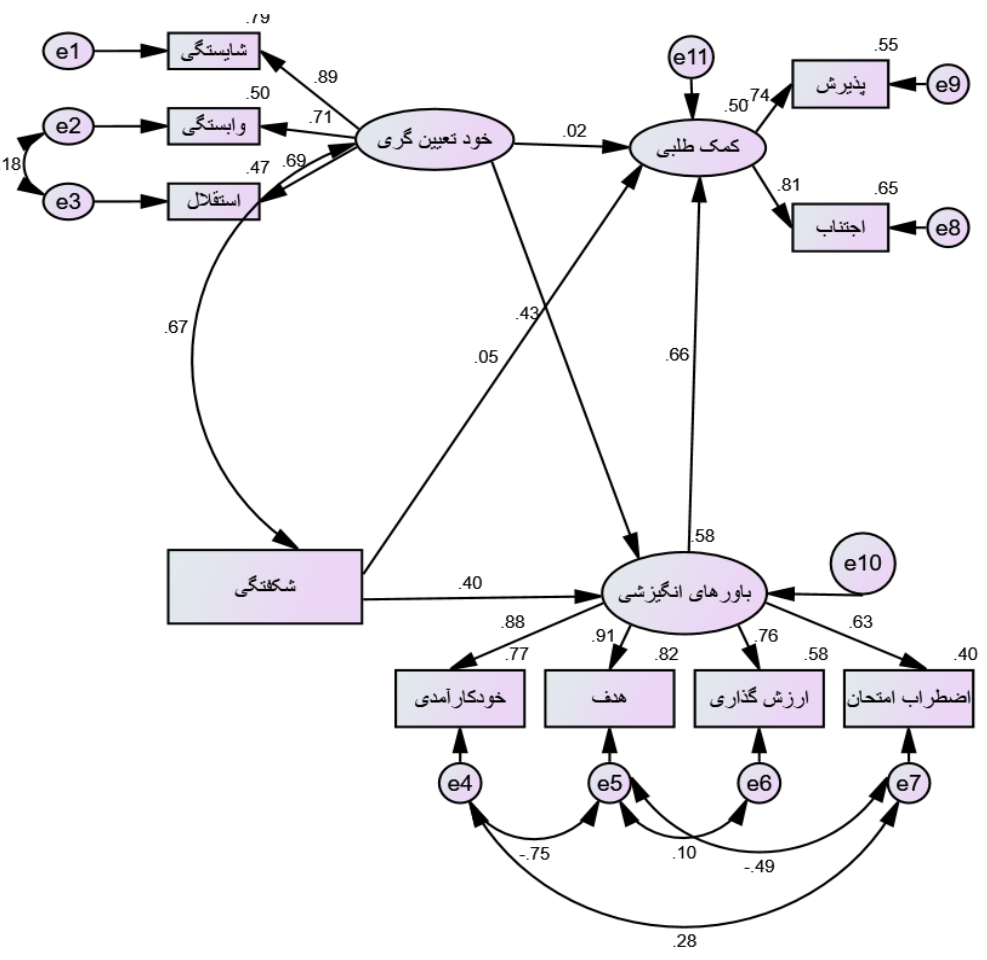

مدل استاندارد اصلاح شده: رابطه كمكك طلبى با خودتعيين كرى و شكفتكى با ميانجى كرى باورهاى انكيزشى در دانش آموزان

جدول "آ: شاخصهاى برازش مدل ساختارى

\begin{tabular}{|c|c|c|c|c|c|c|c|c|c|c|}
\hline SRMR & RMSEA & TLI & NFI & AGFI & GFI & CFI & X2/df & df & $\mathrm{X} 2$ & متغير \\
\hline.$/ .94$ &.$/ 109$ & $\cdot$ / AVG & - / ^৭F & ./VQ9 & $\cdot / M \mu r$ & - /AYA & $9 / 49$ & $\Delta \wedge$ & $r V I / \cdot r r$ & مدل ساختارى قبل از اصلاح \\
\hline .1 .94 & .1 .91 &.$/ 949$ &.$/ Q F V$ & - /AVQ &.$/ Q \mathrm{FT}$ &.$/ 999$ & $r / 91$ & ro & $90 / T Y F$ & مدل ساختارى بعد از اصلاح \\
\hline
\end{tabular}

برازش منـاســبـ مـدل در نظر گرفته شـــه اســت و مقـادير بـالاى //. نشــاندهنده برازش ضـعيف مدل اسـت. همجينين مقدار كاى اسـكوئر برازش شــه ( (Y/9) در سطح I • • معنادار است و شاخص مناسبى براى

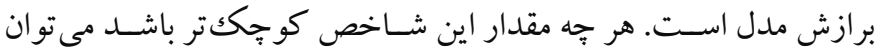
نتيجـه گرفت كه ســاختار كوواريانس مدل بهطور معنادارى از ســاختار كوواريانس مشــاهده شــده متفاوت نيســت. شــاخص نيكويى برازش بّ شـاخص نيكويى برازش تعديل شـدهُ، شاخص برازش هنجارشده، نيز در مدلهاى اصـلاح شـده بالاتر از 9/ • اسـت كه نشان از برازش مناسب مدل دارد. مطابق با نظر كلاين (ها) مقادير كمتر از ^^• • براى شـاخص ريشـه
همانطور كه مشــاهده مى شـود مقادير شــاخصهاى برازش در مدل اصـلاح شده مناسب هستند. با ورود خطاهاى كوواريانس به مدل شاخص برازش مقـايســهاى' (1994.)، و خطاى ريشــه مجذور ميانخين تقريب ( (91. ) به دسـت آمد. اين شـاخص يكى از اصـلى ترين شـاخصهاى برازش مدل در تحليل مدلســازى معادلات ســاختارى اســت كه ميزان نامطلوب بودن مدل برازش شـده رادر مقايسـه با مدل اشـباعشده بر آورد مى كند و مقدار كم اين شـاخص نشـاندهنده برازش مناسـب مدل اسـت. در سـالهاى اخير مقادير زير 9. در سـخت كير انه ترين حالت، دامنه بين · تا هـ/ · بهعنوان دامنه يذيرش

1. Comparative Fit Index (CFI)

2. Root Mean Square Error of Approximation (RMSEA) 
ميانگين مربعات باقيمانده استاندارد شده قابل قبول است. در ادامه ضرايب تأثير مستقيم در مدل گزارش شده است.

جدول ع: نتايج اثرات مستقيم استاندارد

\begin{tabular}{|c|c|c|c|c|c|}
\hline $\mathbf{P}$ & Tاره T T T T & S.E. & برآورد هارامتر & مسيرها & \\
\hline ./^91 &.$/ 1 \% V$ & .1 .94 & $.1 . .9$ & - & خود تعيين گرى \\
\hline.$/ 944$ &.$/ 494$ & $\cdot / \cdot \Delta \Delta$ &.$/ \times 4$ & كمكك طبى & شكفتخى \\
\hline.$/$. & 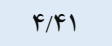 &.$/ .9 Y$ & $\cdot / f \cdot f$ & — & باورهاى انگيزشى \\
\hline 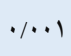 & $F / \mathbb{V}$ & / & . & ـــــباورهاى انخيزشى & خود تعيين گرى \\
\hline$\cdot / \cdot 1$ & $\Delta / 1$. & .1 .91 & $\cdot / \mu \Delta \Delta$ & —— باورهاى انخيزشى & شكفتى \\
\hline
\end{tabular}

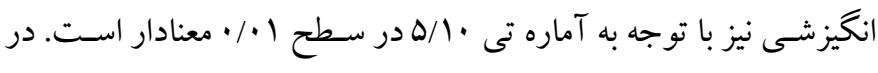

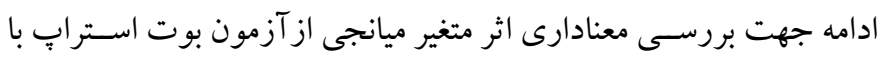
نرمافزار ايموس استفاده شد.

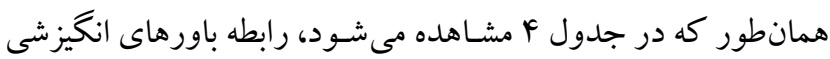

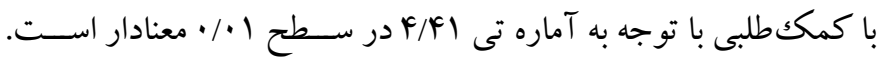

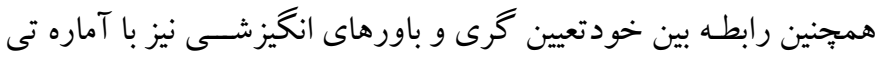
F/TV

جدول 0: نتايج اثرات غير مستقيم خودتعيين كرى و شكفتكى بر كمككطبى از طريق متغير ميانجى باورهاى انكيزشى با روش بوت استراب

\begin{tabular}{|c|c|c|c|c|c|c|}
\hline 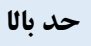 & حد هايين & سطح معنادارى & 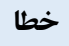 & 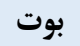 & داده & 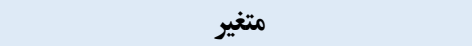 \\
\hline.$/$ THF &.$/ .91$ & 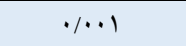 & .1 .9 &.$/ 149$ &.$/ / F V$ & خودتعيين گرى به كمك طلبى از طريق باورهاى انكيزشى \\
\hline ./TrF & $\cdot / \cdot \wedge 1$ & $\%$ & $\cdot / \cdot F$ & . &.$/ 149$ & شكفتخى به كمك طلبى از طريق باورهاى انكيزشى \\
\hline
\end{tabular}

فر اكيران، بـاورهـاى نيرومنـدى دربـاره توانمندى هاى خود براى كســب موفقيت در محيطهاى آموزشسى داشـته باشـند در مواقعى كه براى حل

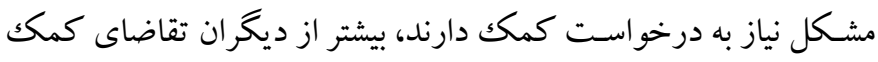

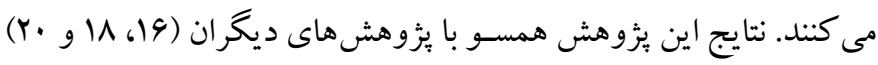

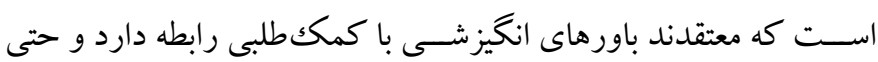

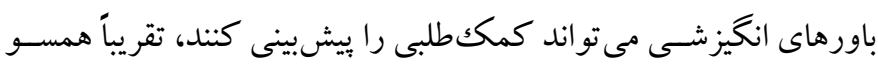
است. در تبيين اين رابطه مى توان بيان كرد كه دانش آموزانى كه معتقدند تو انا هستند، از راهبردهاى شناختى و تلاش بيشترى استفاده مى كنند، و در

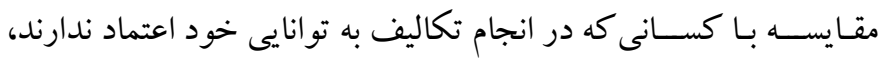

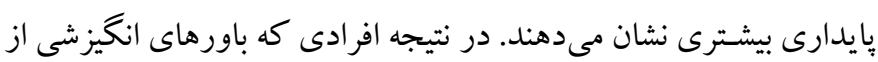

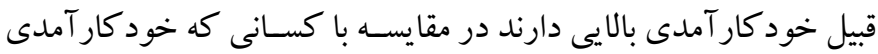
يـايين ترى دارنـد، از كمكك طلبى تحصـيلى به ميزان بيشــترى اســتفاده

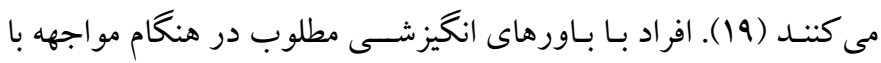

همانطور كه در جدول ها مشــاهده مى شـود حلد بايين براى ميانجى

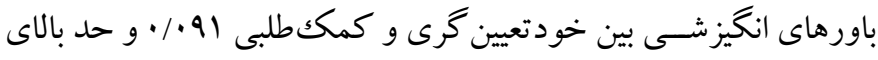

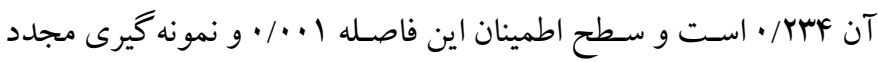

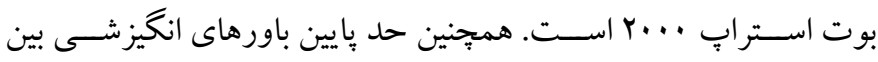

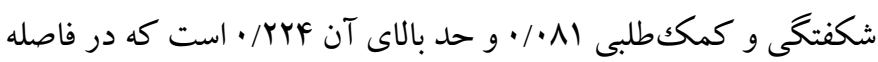

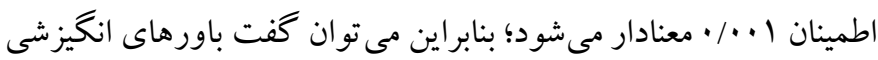

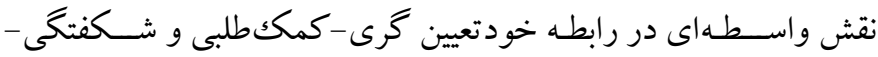
كمككطلبى دارد.

\section{بحث و نتيجه Fيرى}

اين يزوهش با هدف بررسـى روابط ســاختارى كمكك طلبى تحصـيلى دئى

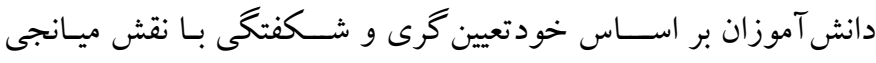

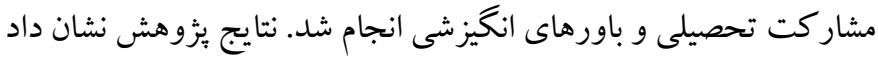

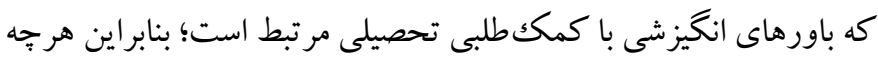


مى تواند دانش آموزان را براى رسسيدن به اهداف برانخيخته كند تا در اين

$$
\text { فرايند از ديخران كمكك بخيرند (Y) (Y). }
$$

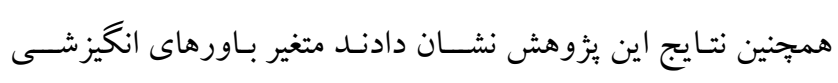

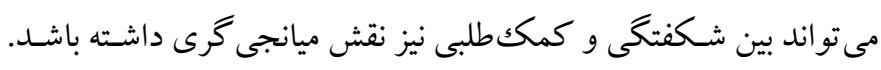

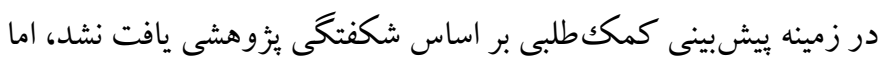

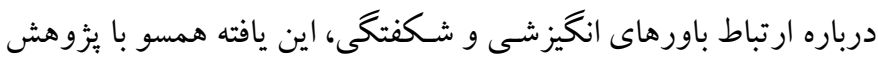

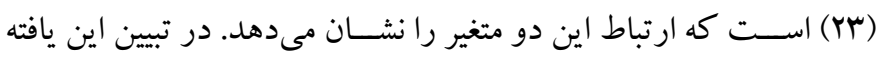

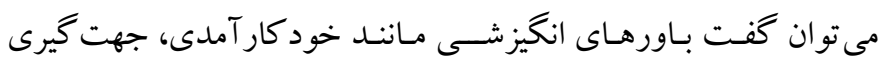

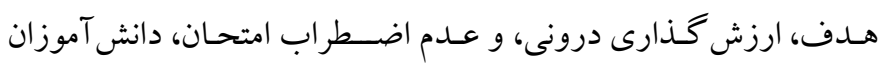

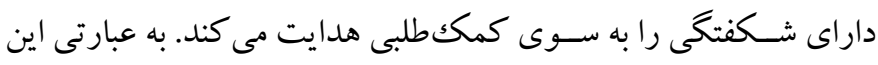

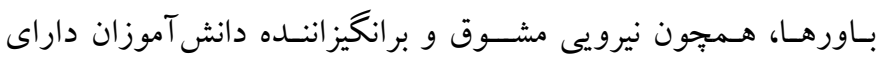

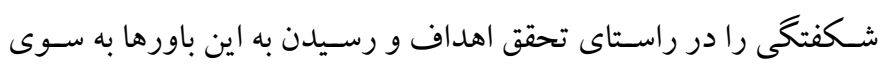

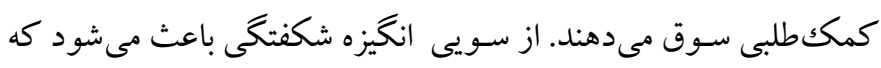

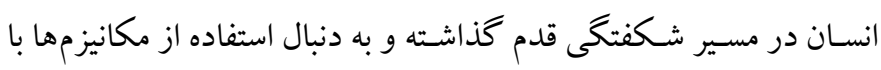

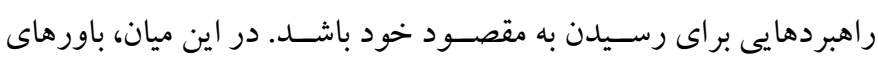

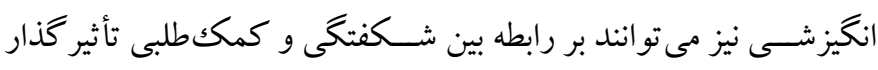

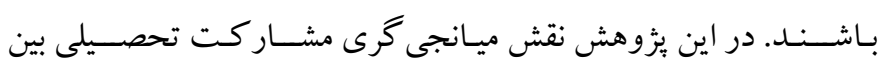

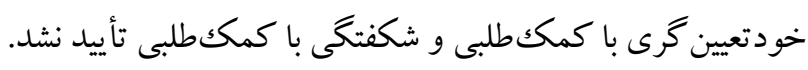

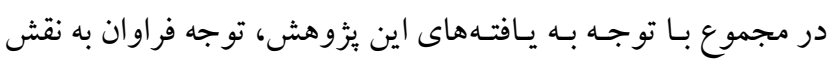

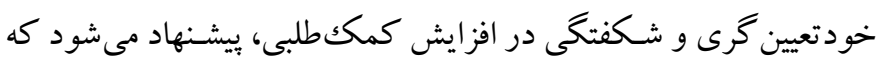

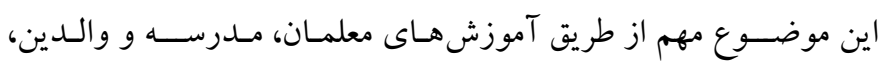

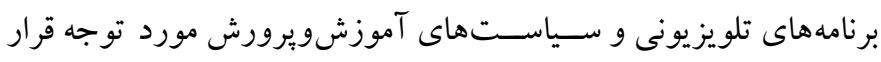

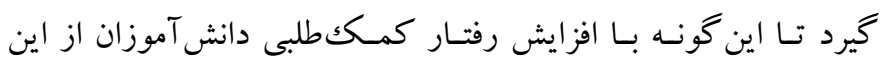

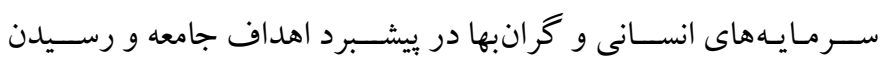
حداكثرى به جامعه آرمانى استفاده شود. عدم كنترل متغير هاى جمعيت شناختى مانند ميزان تحصيلات والدين،

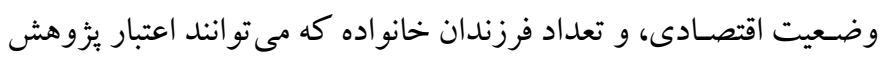

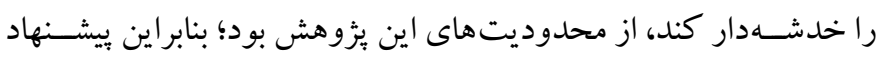
مىشـــود در يثزوهش هاى بعدى تا حد ممكن اين متغيرها كنترل شــوند.

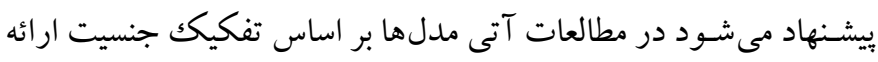

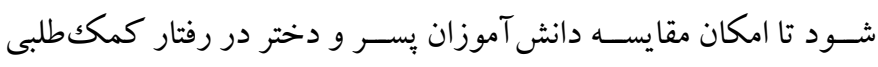

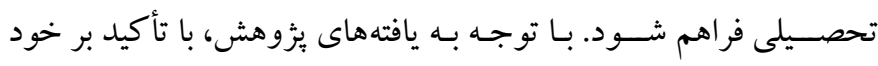

مشـكلات تحصـيلى، به دنبال راهحل هاى مفيد و مناسـب براى حل آن

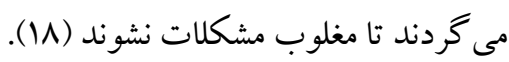

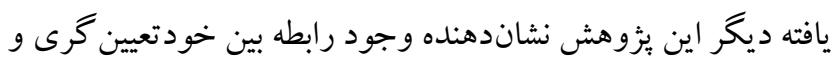

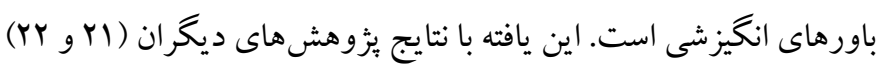

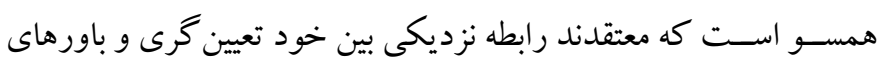

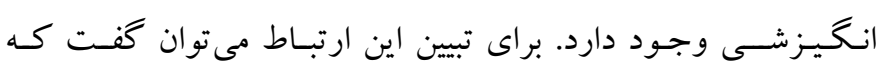

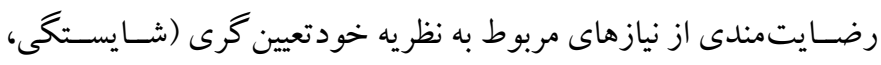

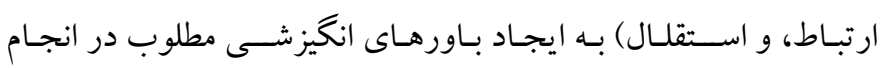
فعاليت هاى تحصيلى و در نهايت موفقيت در تكاليف منجر مى شود؛ زيرا

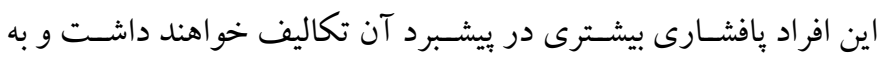

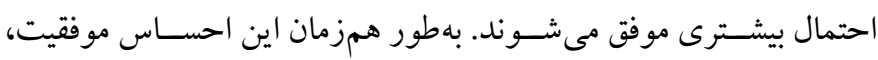

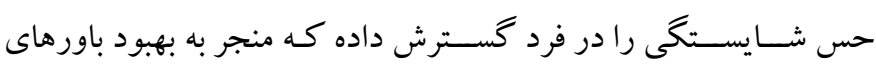
انخيزشى مىشود.

يافته ديخر يثوهش حاضر رابطه بين شكفتخى ود باورهاى انخيزشى را

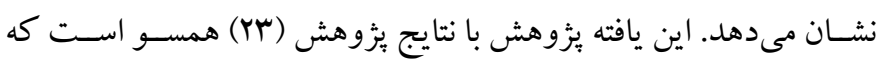

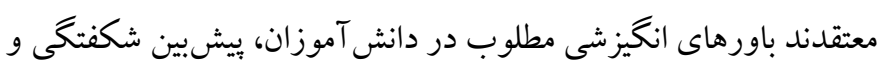

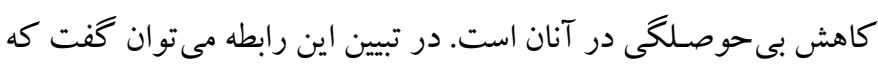

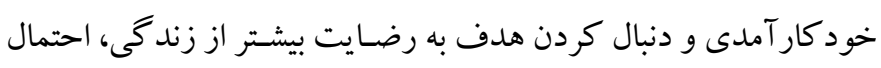

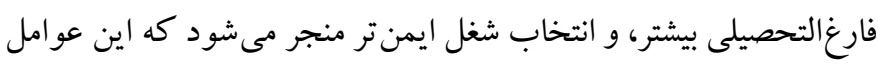
به شكتلىى بيشتر مى انجامد. يافته بعدى بززوهش كه حاصـل اجراى مدل اسـت، نشان داد كه متغير

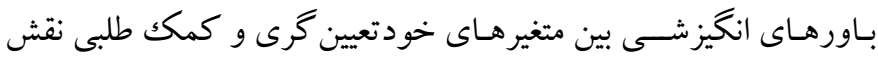

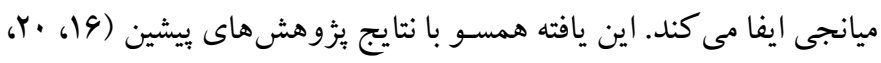

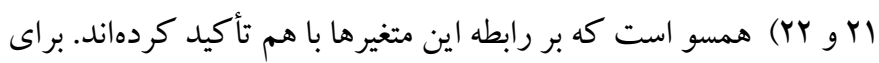

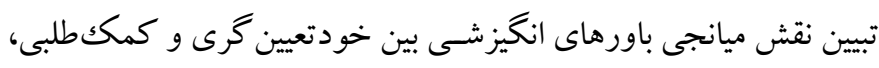

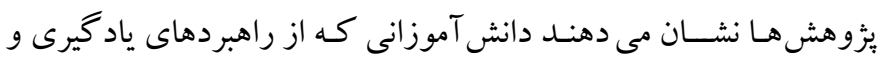

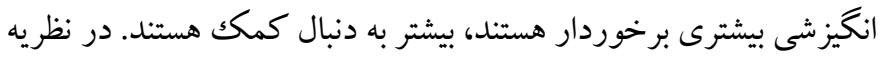

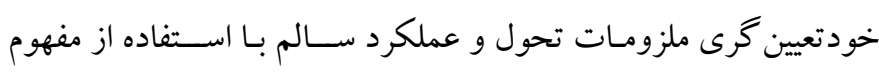

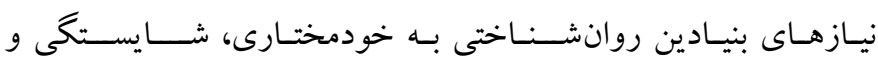

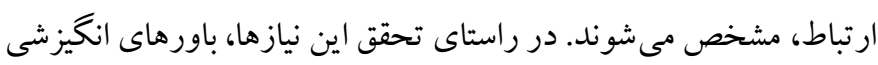
(خود كار آمدى، ارزش تكليف، هدف گذذارى، و عدم اضطئر اب امتحان) 


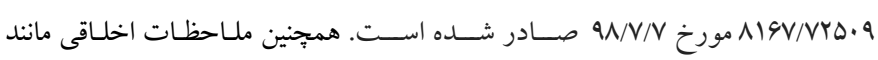

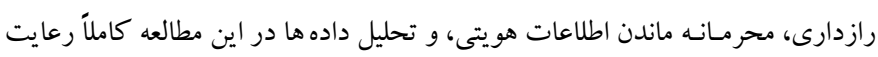
شده است. حامى مالى: اين مطالعه بدون حامى مالى و با هزينه شـصصى نويسـند كان انجام شـده است.

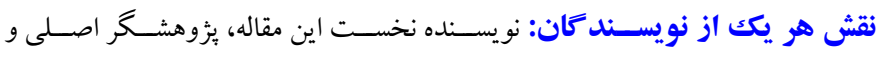

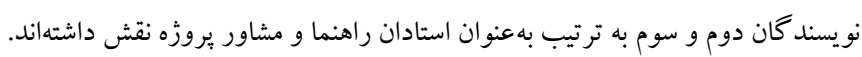

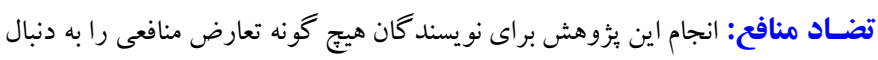

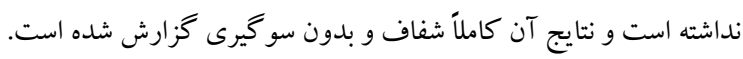

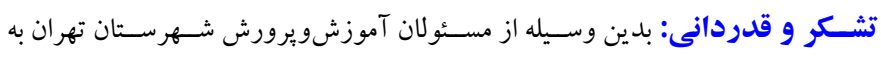

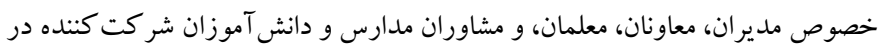
اين يزٔوهش تشكر و قدردانى مىشود.

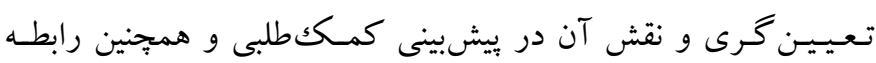
مشــاركت تحصــلى و باورهاى انكيزشــى با كمك طلبى، از اين مدل مى توان براى مشـاركت دادن فعال دانش آموزان در محيط آموزشى و در رسسيدن به هدفهاى تحصسيلى به خصسوص در روشهاى ياد گيرى فعال، اردوهـاى مطسالعـاتى، و كلـاسهـاى تقويتى و در نتيجه در جهت تحكيم

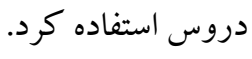

ملاحظات اخلاقى

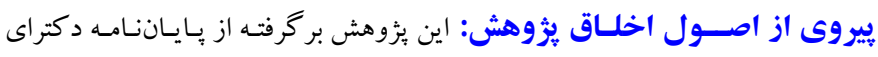

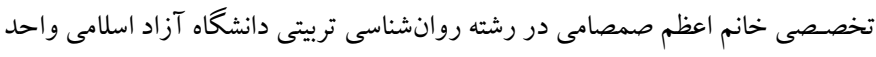

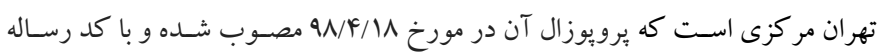

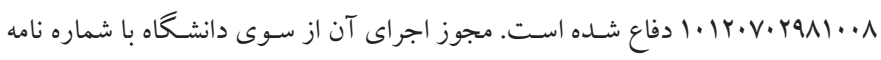




\section{References}

1. Strohmeier D, Gradinger $\mathrm{P}$, Wagner $\mathrm{P}$. Intercultural Competence Development Among University Students from a Self-Regulated Learning Perspective. Zeitschrift für Psychologie. 2017. [Link]

2. Kosyluk KA, Conner KO, Al-Khouja M, Bink A, Buchholz B, Ellefson S, ... \& Corrigan PW. Factors predicting helpseeking for mental illness among college students. Journal of Mental Health. 2021; 30(3): 300-307. [Link]

3. McDermott RC, Smith PN, Borgogna N, Booth N, Granato $\mathrm{S}$, Sevig TD. College students' conformity to masculine role norms and help-seeking intentions for suicidal thoughts. Psychology of Men \& Masculinity. 2018;19(3):340. [Link]

4. Newman RS. Freedom's prophet: Bishop Richard Allen, the AME Church, and the black founding fathers: NYU Press. New York, NY: New York University. 2008.

5. Karabenick SA. Classroom and technology-supported helpseeking: The need for converging research paradigms. Learning and instruction. 2011; 21(2): 290-296. [Link]

6. Holt LJ. Attitudes about help-seeking mediate the relation between parent attachment and academic adjustment in first-year college students. Journal of College Student Development. 2014; 55(4): 418-423. [Link]

7. McDermott RC, Smith PN, Borgogna N, Booth N, Granato $\mathrm{S}$, Sevig TD. College students' conformity to masculine role norms and help-seeking intentions for suicidal thoughts. Psychology of Men \& Masculinity. 2018;19(3):340. [Link]

8. Deci EL. Vansteenkiste M. Self-determination theory and basic need satisfaction: Understanding human development in positive psychology. 2003. [Link]

9. Jalili F. The Effect of Self-determination Training and Gender on Help-seeking of Students. Knowledge \& Research in Applied Psychology. 2019; 20(1): pp. 122-126. [Link]

10. Keyes CLM. Toward a science of mental health. Oxford handbook of positive psychology. New York: Oxford University Press. 2011: 5-12.

11. Ghadampour E., Mirderikvand F, Beyranvand K. The effectiveness of logo therapy training on boredom and flourishing of female high school students. Positive Psychology Research. 2018; 4(2): 1-12. [Link]

12. Deci EL, Ryan RM. Levels of analysis, regnant causes of behavior and well-being: The role of psychological needs. Psychological Inquiry. 2011; 22(1): 17-22. [Link]

13. Reschly A, Christenson SL. School completion. In G.Bear and k. Minke (Eds). Children needs: Development, prevention \& intervention (147-169). Washington DC: National Association of school psychologist. 2006. [Link]

14. Linnenbrink EA, Pintrich PR. The role of self-efficacy beliefs in student engagement and learning in the classroom. Reading \&Writing Quarterly. 2003; 19(2): 119137. [Link]
15. Guhn M, Emerson SD, Gouzouasis P. A population-level analysis of associations between school music participation and academic achievement. Journal of Educational Psychology. 2020; 112(2), 308. [Link]

16. Nasa G, Sharma HL. A study on the impact of academic self-efficacy and academic help-seeking behavior on goal orientation of secondary school students. International Journal of Research in Social Sciences. 2018; 8(4):929940. [Link]

17. Seif MH, Rastegar A, Talebi S, Yadegar M, Qaeedi R. Presenting causal model of goals orientation dimensions relations and academic help-seeking: The role of academic engagement and self-efficiency. Journal of School Psychology. 2020; 9(3): 139-161. [Link]

18. Nowack K. Facilitating successful behavior change: Beyond goal setting to goal flourishing. Consulting Psychology Journal: Practice and Research. 2017; 69(3): 153. [Link]

19. Liou PY, Wang CL, Lin JJ, Areepattamannil S. Assessing students' motivational beliefs about learning science across grade level and gender. The Journal of Experimental Education. 2021; 89(4): 605-624. [Link]

20. Souri Z, Souri Z. The Relationship between Motivational Beliefs and Helpful Behavior and Attitudes Towards Mathematics in Third Grade High School Students in Khorramabad District 1, First International Conference on Development and Promotion of Humanities in Society. Association for Development and Promotion of Basic Sciences and Technologies. 2017. [Link]

21. Wehmeyer ML. Self-determination: A family affair. Family Relations. 2014; 63(1): 178-184. [Link]

22. Jalili F, Arefi M, Qamrani A, Manshii G.The effectiveness of Self-determination Education on Academic Motivation and Academic Flow of Farhangian University Students in Birjand. Journal of Educational Psychology Studies. 2019; 16(34): 58-27. [Link]

23. Ghadampour E, Mirderikvand F, Beyranvand K. The effectiveness of logo therapy training on boredom and flourishing of female high school students. Positive Psychology Research. 2018; 4(2): 1-12. [Link]

24. Ryan AM, Pintrich PR. "Should I ask for help?" The role of motivation and attitudes in adolescents' help-seeking in math class. Journal of educational psychology. 1997; 89(2): 329. [Link]

25. Ghanbari TM, Shikhileslami R, Fouladchang M, Hosseinchari M. Meta Cognitive Knowledge and School Well-Being: The Mediating Role of Academic Helpseeking. Developmental Psychology. 2019; 16(61):49-60. [Persian] [Link]

26. Ilardi BC, Leone D, Kasser T, Ryan RM. Employee and supervisor ratings of motivation: Main effects and discrepancies associated with job satisfaction and adjustment in a factory setting 1 . Journal of applied social psychology. 1993; 23(21): 1789-1805. [Link]

27. Shahsiah N, Rezapour Mirsaleh Y, Safi M. Structural Modelling of the Relationship between Mindfulness, Self- 
Determination, Self-Compassion and Alexithymia in Girl Students Engaged in Self-Injury. Journal of Modern Psychological Researches. 2021; 15(60): 149-169. [Persian] [Link]

28. Diener E, Biswas-Diener R. Happiness: Unlocking the Mysteries of Psychological Wealth. Malden, MA: Blackwell Publishing. 2008: 22-37.

29. Ghadampour E, Mirderikvand F, Beyranvand K. The effectiveness of logo therapy training on boredom and flourishing of female high school students. Positive Psychology Research. 2018; 4(2): 1-12. [Link]

30. Schaufeli WB, Bakker AB, Salanova M. The measurement of work engagement with a short questionnaire: A crossnational study. Educational and psychological measurement. 2006; 66(4):701-16. [Link]

31. Azadi dehbidi F, foolad chang M. Causal Model of Academic Engagement: The Role of Academic Support and
Academic Self-Regulation. Journal of Instruction and Evaluation, 2019; 12(47): 159-183. [Link]

32. Pintrich PR, Zusho A. Student motivation and selfregulated learning in the college classroom. Higher education: Handbook of theory and research: Springer; 2002. p. 55-128. [Link]

33. Chalmeh R, latifiyan M. Characteristics of Metacognitive Learning Environment and Academic Achievement: Investigating the Mediating Role of Motivational Beliefs in Students. Journal of Applied Psychology. 2012; 6(3):43-58. [Persian] [Link]

34. Chou CP, Bentler PM. Estimates and tests in structural equation modeling. 1995: 105-121. [Link]

35. Kline RB. Principles and practice of structural equation modeling: Guilford publications. 2015: 22-41. [Link]

36. Steiger JH. Understanding the limitations of global fit assessment in structural equation modeling. Personality and Individual differences. 2007; 42(5), 893-898. [Link] 